\title{
Effective photosensitized, electrosensitized, and mechanosensitized luminescence of lanthanide complexes
}

\author{
Yasuchika Hasegawa', Yuichi Kitagawa' and Takayuki Nakanishi ${ }^{1}$
}

\begin{abstract}
The $4 f-4 f$ emission of $T b(I I I), E u(I I I)$, and Sm(III) complexes plays an important role in the design of monochromatic green, red, and deep-red luminescent materials for displays, lighting, and sensing devices. The $4 f-4 f$ emission of Yb(III), $\mathrm{Nd}(\mathrm{III})$, and $\mathrm{Er}(\mathrm{III})$ complexes is observed in the near-infrared (IR) region for bioimaging and security applications. However, their absorption coefficients are extremely small $\left(\varepsilon<10 \mathrm{~L} \mathrm{~mol}^{-1} \mathrm{~cm}^{-1}\right)$. In this review, photosensitized luminescent lanthanide(III) complexes containing organic chromophores (ligands) with large absorption coefficients ( $\varepsilon$ $>10,000 \mathrm{~L} \mathrm{~mol}^{-1} \mathrm{~cm}^{-1}$ ) are introduced. Organic molecular design elements, including (1) the control of the excited triplet $\left(T_{1}\right)$ state, (2) the effects on the charge-transfer (CT) band, and (3) the energy transfer from metal ions for effective photosensitized luminescence, are explained. The characteristic electrosensitized luminescence (electroluminescence) and mechanoluminescence (triboluminescence) of lanthanide(III) complexes are also explained. Lanthanide(III) complexes with well-designed organic molecules are expected to open avenues of research among the fields of chemistry, physics, electronics, and material science.
\end{abstract}

\section{Introduction}

Lanthanides comprise a family of highly electropositive period 6 metals. According to the previous literature, lanthanides are defined as lanthanum (La) and 14 other elements (Ce, Pr, Nd, Pm, Sm, Eu, Gd, Tb, Dy, Ho, Er, $\mathrm{Tm}, \mathrm{Yb}$, and $\mathrm{Lu})^{1}$. A general lanthanide is represented by the symbol Ln. Lanthanides in the stable (III) oxidation state are simply characterized by an incompletely filled $4 \mathrm{f}$ shell. The $4 f$ orbital is shielded from the surroundings by the filled $5 s^{2}$ and $5 p^{2}$ orbitals (an image of the $4 \mathrm{f}$ radial distribution function: Fig. 1a). In a configurational coordinate diagram, these levels appear as parallel parabolas (a small offset case: Fig. 1b) because the $4 \mathrm{f}$ electrons are well shielded from their surroundings. Therefore, emission transitions yield sharp lines (full-width at half-maximum, FWHM $<10 \mathrm{~nm}$ ) in different spectra, which is a much different result from that seen for semiconductors,

\footnotetext{
Correspondence: Yasuchika Hasegawa (hasegaway@eng.hokudai.ac.jp) ${ }^{1}$ Division of Applied Chemistry, Faculty of Engineering, Hokkaido University, Hokkaido, Japan
}

transition materials, and organic molecules, as shown in Fig. 1c (in a large-stokes-shift case: FWHM $>50 \mathrm{~nm})^{2,3}$. The emission of light radiation for lanthanide(III) ions comes mainly from electric dipole transitions. Transitions formed in the $4 \mathrm{f}^{\mathrm{i}}$ inner shell of free ions are forbidden because they do not correspond to a change in parity. However, the transitions that are forbidden by odd-parity states become partially allowed by the mixing of the $4 f$ and $5 d$ orbitals through the ligand field. Since the parity does not change dramatically in such a transition, the lifetime of the excited state is long ( $\tau>\mathrm{ms}$ ).

Lanthanide complexes with attached organic ligands are regarded as attractive luminescent materials because of their characteristic narrow emission bands and long emission lifetimes over a wide range of wavelengths (ultraviolet/visible/near-infrared (UV/vis/near-IR)). The 4f-4f emissions from $\mathrm{Tb}(\mathrm{III}), \mathrm{Eu}(\mathrm{III})$, and $\mathrm{Sm}(\mathrm{III})$ complexes play an important role in the design of monochromatic green, red, and deep-red luminescent materials for displays, lighting, and sensing devices, respectively 


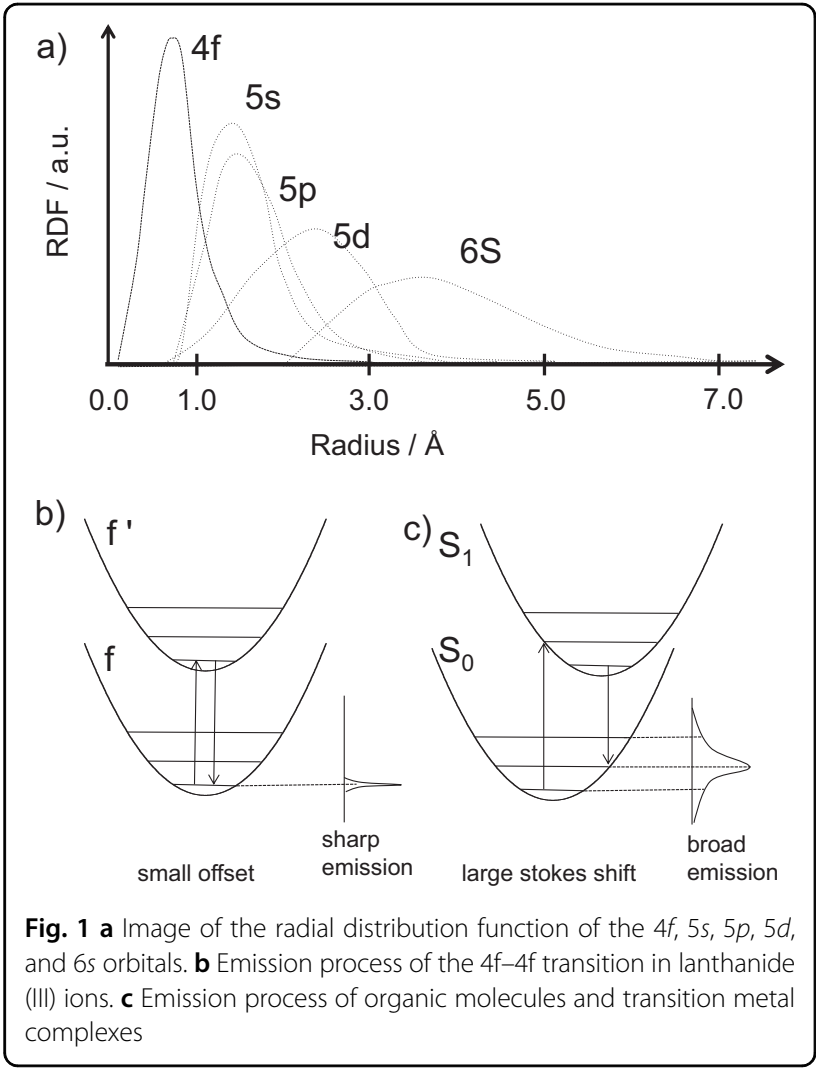

(Fig. 2a, b $)^{3-8}$. The near-IR 4f-4f luminescence of $\mathrm{Nd}(\mathrm{III})$, $\mathrm{Er}(\mathrm{III})$, and $\mathrm{Yb}(\mathrm{III})$ complexes with long emission lifetimes is useful in bioimaging applications (Fig. 2c) ${ }^{8}$. Effective wavelength converters using lanthanide complexes for silicon solar cells have also been reported (Fig. 2d) ${ }^{9,10}$.

Here, we introduce the history of lanthanide complex studies. The 1930s and early 1940s witnessed the first spectroscopic studies of lanthanide ions in solution. Freed and co-workers ${ }^{11}$ found that the relative intensities of the absorption bands of $\mathrm{Eu}(\mathrm{III})$ were different in different solvents, and Weissman ${ }^{12}$ observed that complexes of Eu (III) with certain UV absorbing ligands were highly luminescent when excited with UV light. Since Eu(III) itself shows only a few very weak absorption bands, the solution of this ion does not offer very bright luminescence. Obviously, certain organic ligands can photosensitize the luminescence of lanthanide ions. It was also found that lanthanide ions quench the fluorescence of organic ligands ${ }^{13}$. Such studies can be considered as the starting points for the research and development of luminescent lanthanide complexes. It took, however, approximately 20 years for photochemists and coordination chemists to take a serious interest in these materials. At the beginning of the 1980s, the field received a new impulse when it became clear that lanthanide complexes could find widespread use in medical diagnostics ${ }^{14}$. In the past 40 years, lanthanide ions also started to receive the
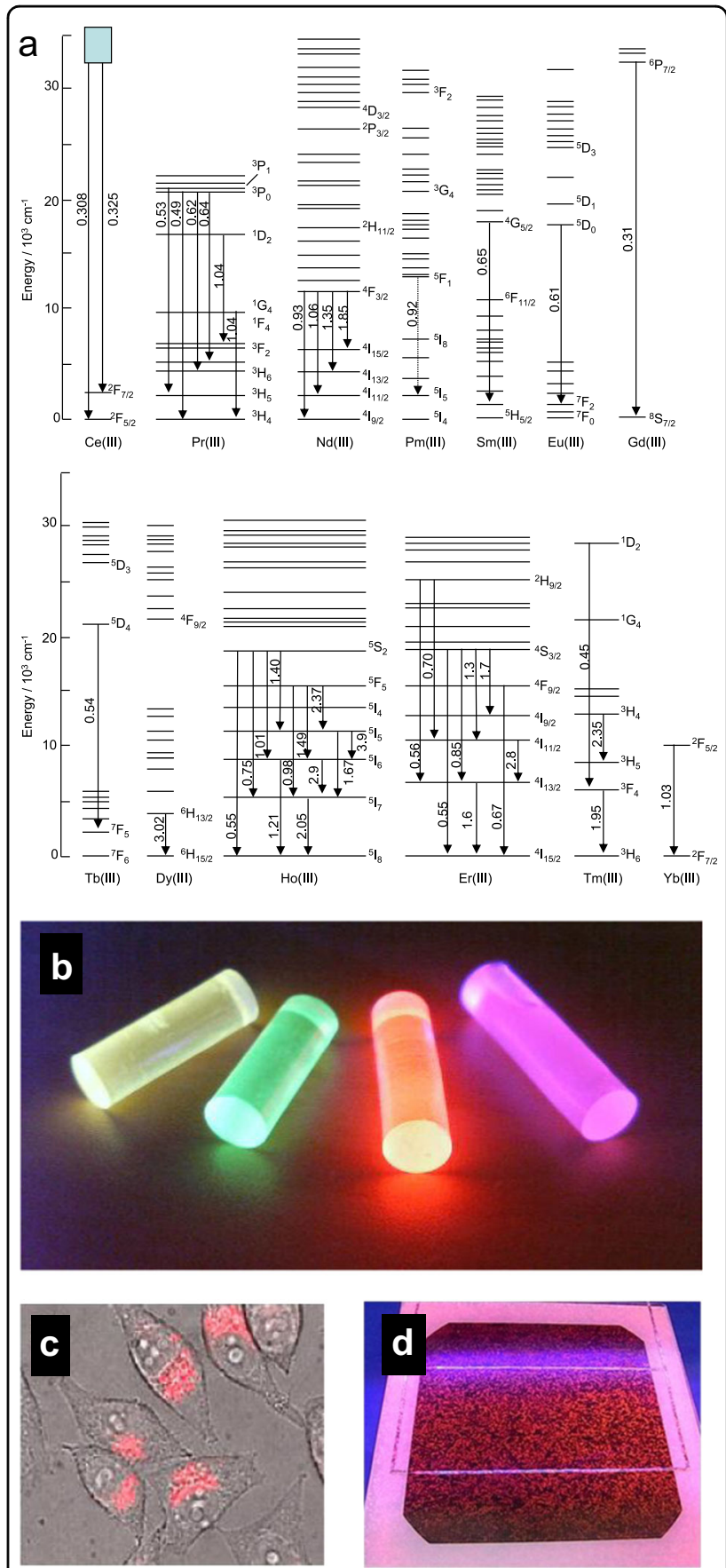

Fig. 2 a Emission processes in the energy diagrams of lanthanide(III) ions. $\mathbf{b}$ Luminescent plastics using $\mathrm{Tb}$ (III) and Eu(III) complexes and polymethylmethacrylate. c Bioimaging using a Eu(III) complex. Reprinted with permission from Bünzli et al ${ }^{8}$. Copyright 2010 Royal Society of Chemistry. $\mathbf{d}$ Luminescent EVA film containing Eu(III) complexes on a silicon solar cell. Reprinted with permission from Hasegawa et al ${ }^{9}$. Copyright 2015 SPST

attention of the growing number of organic and supramolecular chemists. At the present stage, many types of luminescent lanthanide complexes have been reported $^{15,16}$. 


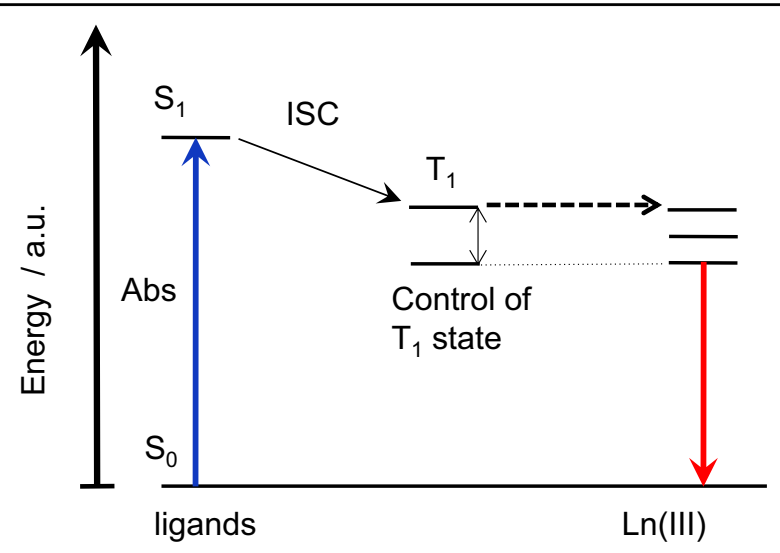

Fig. 3 Photosensitized emission process of a lanthanide(III) complex attached with $\pi$-conjugated organic ligands

The focus of this review is photosensitized and electrosensitized luminescence of lanthanide complexes with effective organic ligands. The absorption coefficients of $4 \mathrm{f}-4 \mathrm{f}$ transitions in $\mathrm{Ln}(\mathrm{III})$ ions are extremely small $(4 \mathrm{f}-4 \mathrm{f}$ transition bands: $\left.\varepsilon<10 \mathrm{~L} \mathrm{~mol}^{-1} \mathrm{~cm}^{-1}\right)$. The photosensitized and electrosensitized energy transfer from an organic ligand to a lanthanide(III) ion is a key point for achieving effective luminescence of lanthanide(III) complexes. Various types of organic chromophores (ligands) have been developed to photosensitize the luminescence of lanthanide(III) ions. Luminescent lanthanide(III) complexes with large absorption coefficients $\left(\pi-\pi^{*}\right.$ transition band: $\varepsilon>10,000 \mathrm{~L} \mathrm{~mol}^{-1} \mathrm{~cm}^{-1}$ ) have been promising molecules as luminescent materials in the fields of optoelectronics, analytical chemistry, photophysical, and biomedical science.

Organic molecular designs that include (1) the control of the excited triplet $\left(\mathrm{T}_{1}\right)$ state, (2) the effect on the charge-transfer (CT) band, and (3) the energy transfer from metal ions for effective photosensitized luminescence are explained in the next chapter. The transition bands provide effective photosensitized luminescence of lanthanide complexes. We also summarize the electroluminescence (EL) and mechanoluminescence of lanthanide(III) complexes as energy transfer from the electroexcitation of the organic ligand. The EL of lanthanide(III) complexes has been studied for the development of display devices. The historical reports and recent progress of EL using lanthanide complexes are introduced in this review.

The mechanoluminescence of lanthanide(III) complexes has also been studied over the past several decades. Mechanoluminescence is also called triboluminescence, which is the emission of light from bulk solid materials that originates from mechanical stress. While there have been extensive discussions on the origin of triboluminescence in molecular crystals, some studies have indicated a contribution from the piezoelectric effect upon breaking non-centrosymmetric bulk crystals. Their EL and mechanoluminescence are dependent on the energy transfer process from the ligands in lanthanide complexes.

The molecular design and the strategies for the development of strong luminescent lanthanide(III) complexes are reviewed to illustrate novel developments in the fields of molecular science, photophysics, electronics, and material science.

\section{Photosensitized luminescence from an organic ligand \\ Control of the $T_{1}$ state}

First, we introduce the photosensitized energy transfer from organic ligands to lanthanide ions for the development of a strong luminescent lanthanide(III) complex. Effective photosensitized energy transfer is achieved by excitation at the $\pi-\pi^{*}$ bands of organic ligands. The $\pi-\pi^{*}$ bands of organic ligands can transition and have large absorption coefficients $\left(\varepsilon>10,000 \mathrm{~L} \mathrm{~mol}^{-1} \mathrm{~cm}^{-1}\right)$. In the case of a lanthanide(III) complex, the $S_{1}$ state of the organic ligand irradiated at the $\pi-\pi^{*}$ band rapidly changes to a $T_{1}$ state because of the heavy metal effect of the lanthanide(III) ions. For this reason, energy transfer efficiency between the $\mathrm{T}_{1}$ state and lanthanide(III) ion is key for effective photosensitization.

Here, the photosensitized energy transfer process is explained by using a simple schematic diagram (Fig. 3). First, the organic ligand in the lanthanide(III) complex is excited by photoirradiation at the $\pi-\pi^{*}$ transition band, and then, a $T_{1}$ state of the ligand is formed. The energy transfer process between the $\mathrm{T}_{1}$ and $4 \mathrm{f}-4 \mathrm{f}$ transition bands of the lanthanide ion $\left(4 f-4 f^{\prime}\right)$ is generally explained by the Förster and Dexter mechanisms ${ }^{15,16}$. Effective energy transfer (forward energy transfer) between the $\mathrm{T}_{1}$ (donor) and $4 \mathrm{f}-4 \mathrm{f}^{\prime}$ (acceptor) leads to the formation of an excited Ln(III) complex. However, a small energy gap between the $T_{1}$ state and emitting level of the $\operatorname{Ln}(\mathrm{III})$ ion promotes energy back transfer from the $4 f-4 f^{\prime}$ emitting level (donor) to the $\mathrm{T}_{1}$ state (acceptor), resulting in the prevention of effective forward energy transfer. Thus, effective energy transfer is dependent on the energy gap between the $T_{1}$ state and the emitting level in lanthanide (III) complexes.

In $\mathrm{Eu}(\mathrm{III})$ complexes with $\beta$-diketonate, pyridyl, and carboxylate ligands, the ideal energy gaps between the $T_{1}$ state and the emitting level (Tb(III): ${ }^{7} \mathrm{~F}_{6}-{ }^{5} \mathrm{D}_{4}, \mathrm{Eu}(\mathrm{III})$ : ${ }^{7} \mathrm{~F}_{0^{-}}{ }^{5} \mathrm{D}_{0}$ ) for the suppression of energy back transfer are estimated to be more than 2400 and $2500 \mathrm{~cm}^{-1}$, respectively ${ }^{17-24}$, although effective energy transfer with a small energy gap between the $T_{1}$ state and emitting level $\left({ }^{7} \mathrm{~F}_{0^{-}}{ }^{5} \mathrm{D}_{0}\right)$ has also been reported ${ }^{22,23}$. The effective energy 


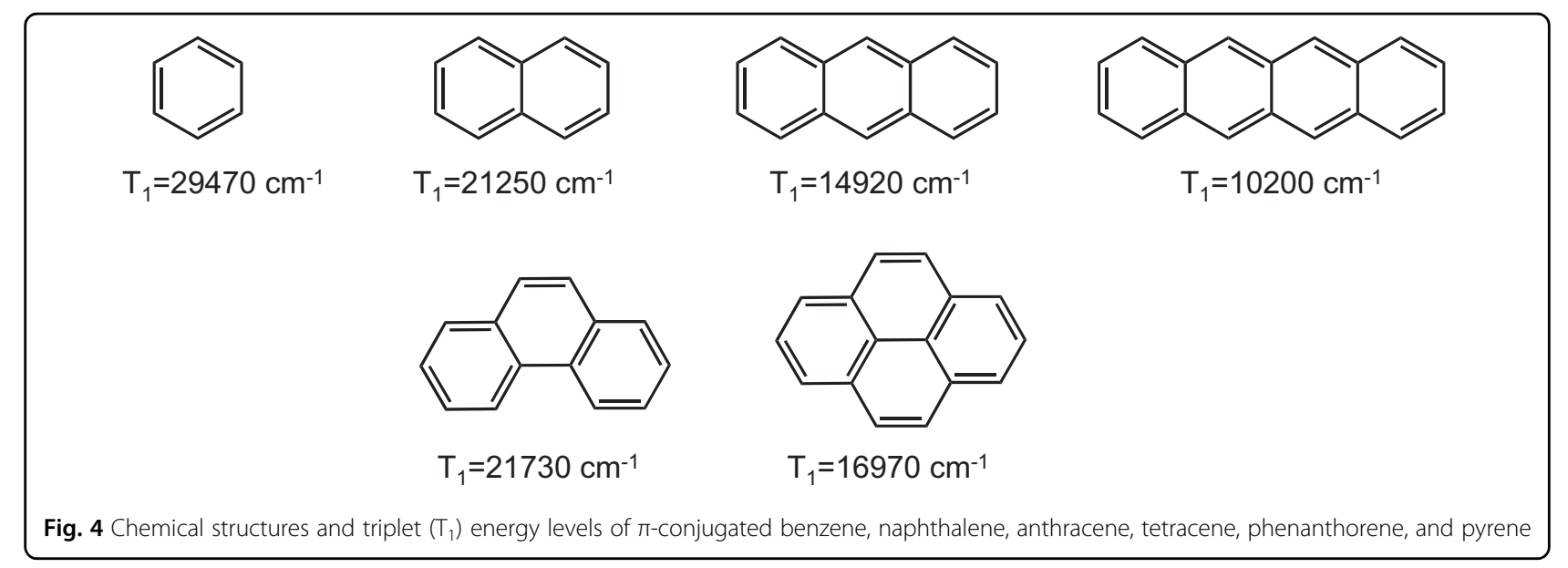

transfer between an organic ligand and lanthanide(III) ion is dependent on the ligand moiety.

Generally, the expansion of the $\pi$-conjugated system in a ligand leads to a decrease in the $T_{1}$ level. However, the emitting level of lanthanide(III) ion is not changed by the surrounding media, such as an organic ligand and solvent. The emitting levels of the $\mathrm{Eu}(\mathrm{III}), \mathrm{Tb}(\mathrm{III}), \mathrm{Sm}(\mathrm{III}), \mathrm{Yb}(\mathrm{III})$, $\mathrm{Nd}(\mathrm{III})$ and $\mathrm{Er}(\mathrm{III})$ ions have been estimated to be 17,293, $20,500,17,900,10,260,11,100$, and $6535 \mathrm{~cm}^{-1}$, respectively ${ }^{3}$. When the energy level of the $T_{1}$ state is lower than that of the emitting level, the lanthanide complex does not emit photons. Typical $\pi$-conjugate systems and their $\mathrm{T}_{1}$ energy levels are summarized in Fig. $4^{25-27}$. When the energy gap between the $T_{1}$ and the emitting levels is also $<2500 \mathrm{~cm}^{-1}$, energy back transfer from $\operatorname{Ln}$ (III) to the ligand is observed. From the photophysical findings, the expansive limitation of the $\pi$-conjugate structure in an organic ligand should be required for effective energy forward transfer from the $T_{1}$ state of an organic ligand to the emitting level of a lanthanide(III) ion.

The overall emission quantum yield of an $\operatorname{Ln}(\mathrm{III})$ complex excited at the $\pi-\pi^{*}$ band of an organic ligand, $\Phi_{\pi-\pi^{*}}$, is calculated as follows:

$$
\Phi_{\pi-\pi^{*}}=\Phi_{f-f} \times \eta_{\text {sens }}=\frac{k_{r}}{k_{r}+k_{n r}} \times \eta_{\text {sens }},
$$

where $\Phi_{\mathrm{f}-\mathrm{f}}, \eta_{\mathrm{sens}}, k_{\mathrm{r}}$, and $k_{\mathrm{nr}}$ are the lanthanide(III)-centered emission quantum yield, efficiency of the sensitization process, and radiative and non-radiative rate constants, respectively. Knag et al. ${ }^{28}$ reported the photosensitized luminescence of $\mathrm{Nd}(\mathrm{III}), \mathrm{Yb}(\mathrm{III})$, and $\operatorname{Er}(\mathrm{III})$ complexes with anthracene-attached diketonate ligands. The $\eta_{\text {sens }}$ values of the $\mathrm{Nd}(\mathrm{III})$ and $\mathrm{Er}$ (III) complexes were estimated to be $0.89 \%$ and $0.086 \%$, respectively (Fig. $5 \mathrm{a}$ ). Reddy and co-workers ${ }^{29}$ described efficient photosensitized energy transfer of $\mathrm{Nd}(\mathrm{III})$ complexes with pyrene-attached diketonate ligands $\left(\eta_{\text {sens }}\right.$ of $\mathrm{Nd}(\mathrm{III})$ complex: 44\%) (Fig. 5b). He also showed highly efficient photosensitized energy transfer of $\mathrm{Eu}(\mathrm{III})$ complexes with phenanthrene-attached diketonate (Fig. $5 \mathrm{c})^{30}$. In another case, the photosensitized luminescence of $\mathrm{Eu}(\mathrm{III})$ and $\mathrm{Tb}$ (III) ions with triphenylene in calix [4] arene systems has been reported (Fig. 5d) ${ }^{31}$ however, the expansion of $\pi$ conjugated systems in aromatic ligands leads to a decrease in the energy level of the $T_{1}$ state, resulting in energy back transfer from the excited $\operatorname{Ln}(\mathrm{III})$ ions to the $\mathrm{T}_{1}$ state of the aromatic ligands.

We have suggested a novel molecular strategy for the expansion of $\pi$-conjugated systems for the effective photosensitization of a lanthanide(III) complex using a helical-shaped helicene unit (Fig. 5e) ${ }^{32,33}$. We here explain the concept of molecular design for the effective photosensitization of a lanthanide(III) complex. The equation for the $\mathrm{T}_{1}\left(-\mathrm{S}_{0}\right)$ level of the molecules is as follows:

$$
E\left(T_{1}\right)=E_{f}-E_{i}-J_{i j},
$$

where $E$ is the orbital energy and $J$ is a coulombic integral that represents the electrostatic repulsion between the orbital charge distributions. The subscripts $i$ and $f$ are the occupied and unoccupied orbitals related to the $\mathrm{T}_{1}$ states, respectively. The $J_{i f}$ value tends to decrease with the increasing delocalization of the electronic orbital density, when the $\pi$-conjugated system is extended. Herein, we consider a simple molecular design for maintaining the highest occupied molecular orbital (HOMO) and lowest unoccupied molecular orbital (LUMO) energy levels for extended $\pi$-conjugated systems using the fragment molecular orbital (FMO) method and DFT calculations (Gaussian 03, B3LYP/6-31G(d)) ${ }^{34,35}$.

As a standard for $\pi$-conjugated molecules, we used naphthalene, which has a higher energy of the excited state $\left(21,250 \mathrm{~cm}^{-1}\right)$ than those of the emitting levels of $\mathrm{Eu}(\mathrm{III}), \mathrm{Tb}(\mathrm{III})$, and $\mathrm{Sm}(\mathrm{III})$ ions. Extending the $\pi$ conjugation by coupling naphthalene and butadiene results in anthracene or phenanthrene molecules. For phenanthrene, the HOMOs $(5.79$ and $6.19 \mathrm{eV})$ and 


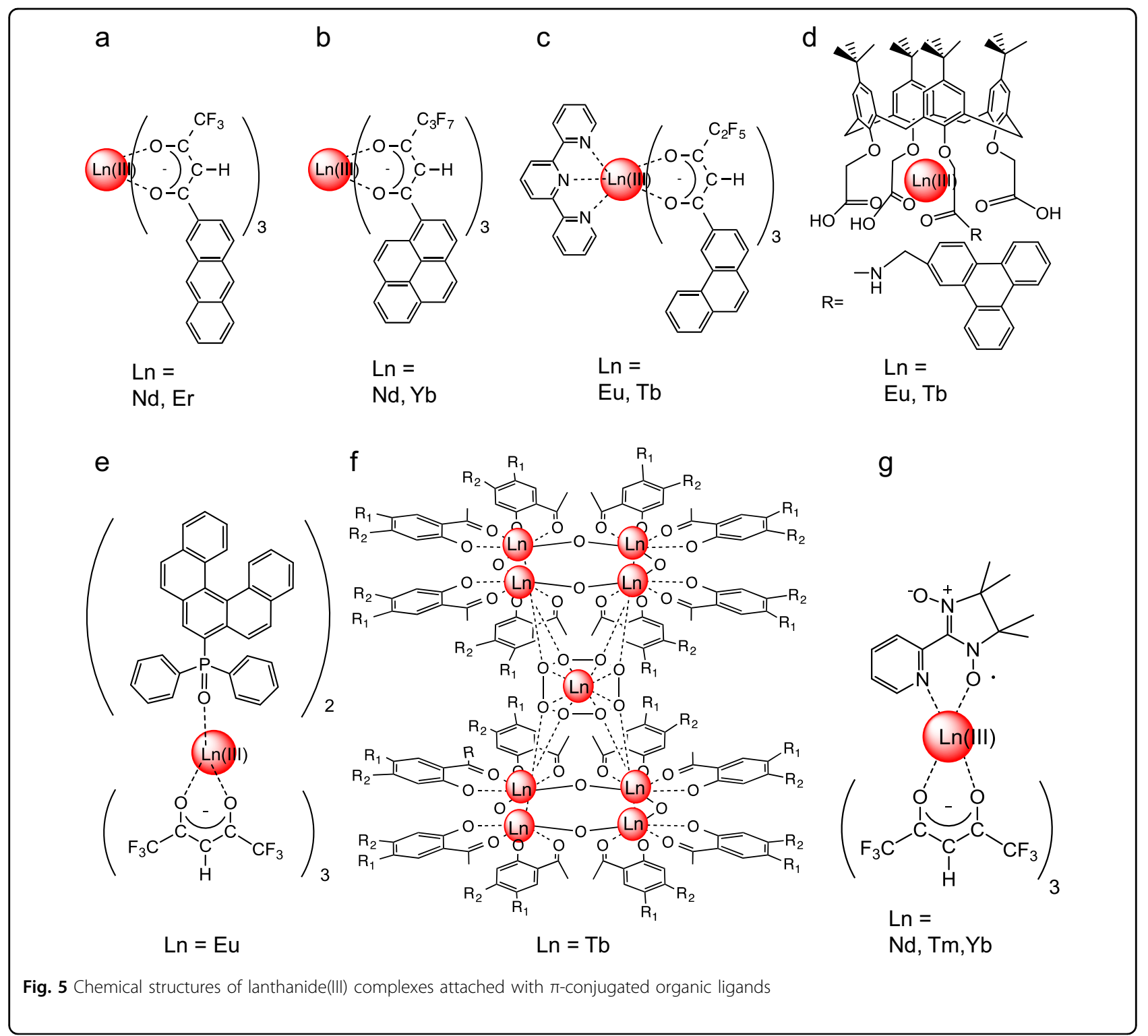

LUMOs $(0.96$ and $0.82 \mathrm{eV})$ are electronically coupled, resulting in nearly unchanged $\operatorname{HOMO}(5.73 \mathrm{eV})$ and LUMO $(0.99 \mathrm{eV})$ energies relative to those of naphthalene. Therefore, the $\mathrm{T}_{1}$ level of phenanthrene is almost unchanged $\left(21,740 \mathrm{~cm}^{-1}\right)$. Based on this conceptual design, an extended $\pi$-conjugated structure by coupling phenanthrene and butadiene provides [4]-helicene $\left(\mathrm{T}_{1}=\right.$ $19,980 \mathrm{~cm}^{-1}$ ). By using the molecular design based on the FMO and DFT, we successfully synthesized a phosphine oxide ligand containing a helical [5]-helicene unit (HPO ligand, $\left.\mathrm{T}_{1}=18,410 \mathrm{~cm}^{-1}\right)^{32}$. For an $\mathrm{Eu}(\mathrm{III})$ complex with an HPO ligand, $\left[\mathrm{Eu}(\mathrm{hfa})_{3}(\mathrm{HPO})_{2}\right]$ (hfa: hexafluoroacetylacetonate), the longer wavelength excitation $\left(\lambda_{\mathrm{ex}}=430 \mathrm{~nm}\right)$ of the HPO ligands induces the photosensitized luminescence of the $\mathrm{Eu}(\mathrm{III})$ complex $\left(\eta_{\text {sens }}=\right.$ 10\%) (Fig. 5e) (2,33. $^{3}$.
We also reported the effective photosensitized luminescence of $\mathrm{Eu}(\mathrm{III})$ and $\mathrm{Tb}(\mathrm{III})$ nonanuclear clusters with 16 salicylate derivative ligands (Fig. 5f) ${ }^{36,37}$. The $\mathrm{Tb}(\mathrm{III})$ clusters showed large absorption coefficients $(\varepsilon>55,000$ $\left.\mathrm{M}^{-1} \mathrm{~cm}^{-1}\right)$. The photosensitized energy transfer efficiency is dependent on the $T_{1}$ state of the aromatic ligands. The emission quantum yield of $\mathrm{Tb}-4$ methylsalycylate $\left(\mathrm{R}_{1}=\mathrm{H}, \quad \mathrm{R}_{2}=\mathrm{CH}_{3}: \Phi_{\pi-\pi^{*}}=31 \%\right)$ was found to be 13 times larger than that of $\mathrm{Tb}-5$ methylsalycylate $\left(\mathrm{R}_{1}=\mathrm{CH}_{3}, \mathrm{R}_{2}=\mathrm{H}: \Phi_{\pi-\pi^{*}}=2.4 \%\right)$. The photophysical characterization and DFT calculations revealed the effect of the methyl group on the electronic structure of the methyl salicylate ligand.

Photosensitized luminescence of lanthanide(III) complexes with $\pi$-conjugated radical ligands has also been reported (Fig. $5 \mathrm{~g})^{38-40}$. The $\pi$-conjugated radial ligands 


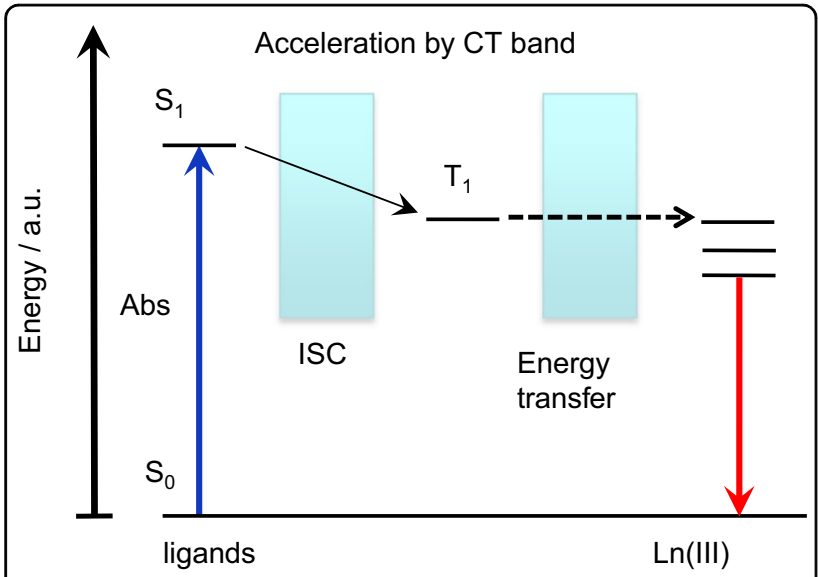

Fig. 6 Photosensitized emission process of a lanthanide(III) complex assisted with charge-transfer (CT) bands

show large absorption coefficients; however, the absorption bands of radical ligands are generally lying in the vis region (wavelength $>700 \mathrm{~nm}$ ). The absorption bands in the vis region prevent the photosensitized luminescence of $\mathrm{Eu}(\mathrm{III})$ and $\mathrm{Sm}$ (III) complexes $^{38}$. Near-IR luminescence of $\mathrm{Nd}(\mathrm{III}), \mathrm{Tm}(\mathrm{III})$, and $\mathrm{Yb}(\mathrm{III})$ complexes with radical ligands has been reported ${ }^{39,40}$. The control and consideration of the energy level of the lowest excited state in an organic chromophore are the most important aspects for developing strong luminescent lanthanide(III) complexes.

\section{Effect on CT band}

The photosensitized luminescence of lanthanide complexes is influenced by a specific band, for example, the CT band in a lanthanide complex. The CT band located in the vis region affects the effective energy transfer from the ligand to the lanthanide(III) ion. The CT transition is categorized into three types: (1) intra-ligand CT (intraLCT), (2) inter-ligand CT (inter-LCT), and (3) ligand-tometal CT (LMCT). The CT bands affect the intersystem crossing process or the energy transfer process between the ligand and the lanthanide(III) ion (Fig. 6).

According to the photosensitized luminescence of lanthanide(III) complexes accelerated by intra-LCT, Eu(III), $\mathrm{Yb}(\mathrm{III}), \mathrm{Nd}(\mathrm{III})$, and $\mathrm{Er}(\mathrm{III})$ complexes with donor amineattached diketonate ligands have been reported $\left(\Phi_{\pi-\pi^{*}}\right.$ : $\mathrm{Nd}=0.0078 \%, \mathrm{Yb}=0.04 \%$, Fig. $7 \mathrm{a})^{41,42}$. The effective luminescence of lanthanide(III) complexes with donor pyridine-attached ligands has been reported $\left(\Phi_{\pi-\pi^{*}}\right.$ : Eu $=$ $43 \%, \mathrm{Nd}=0.22 \%, \mathrm{Yb}=0.59 \%$, Fig. $7 \mathrm{~b})^{43}$. Lanthanide(III) complexes with donor pyridine-attached ligands also show solvatochromic properties, which are dependent on the organic solvent as a sounding medium.

The first example of photosensitized energy transfer from inter-LCT was presented using $\mathrm{Eu}(\mathrm{III})$ and $\mathrm{Tb}(\mathrm{III})$ complexes with hfa ligands in a solid ${ }^{44}$. The emission quantum yield and energy transfer efficiency of the $\mathrm{Eu}(\mathrm{III})$ complex were estimated to be $58 \%$ and $81 \%$, respectively. The effective formation of an inter-LCT state using an Eu (III) complex with phenanthroline ligands was later observed $^{45}$. The inter-LCT-supported near-IR luminescence of $\mathrm{Yb}(\mathrm{III}), \mathrm{Nd}(\mathrm{III})$, and $\operatorname{Er}(\mathrm{III})$ complexes using crown-type ligands was also reported (Fig. 7c ${ }^{46}$.

Generally, effective photosensitized luminescence accelerated by intra- and inter-LCT bands is observed in the solid state. Eliseeva et al. ${ }^{44}$ recently reported that the formation of low-lying inter-LCT states contributes to the improvement of the ligand-to-metal energy transfer efficiency. Characteristic intra-LCT and inter-LCT bands are formed in the tightly packed crystals. The tightly packed crystals can be built as a polymeric structural design with a large strain in the $\pi$-conjugated ligands. The wavelength of the inter-LCT transition band of the strained ligand in solid media is longer than that of corresponding $\pi-\pi^{*}$ transition bands of a normal ligand in liquid media. We observed an effective inter-LCT band using Eu(III) coordination polymers (Fig. 7 d $)^{47}$. The coordination polymers were composed of luminescent $\mathrm{Eu}(\mathrm{hfa})_{3}$ parts and joint organic ligands, bipypo (bipypo: 3,3'-bis(diphenylphosphoryl)-2,2'-bipyridine). The effective inter-LCT band of the diketonate ligands was observed at approximately 400 $\mathrm{nm}$ in the solid state. The quantum efficiency accelerated by the inter-LCT in the solid state, $\Phi_{\pi-\pi \pi^{*}}$ was found to be $61 \%$. We also consider that luminescent lanthanide(III) coordination polymers with a characteristic inter-LCT band can be constructed by a zig-zag chained polymer. The tightly packed zig-zag structure of the Eu(III) coordination polymers was prepared using zig-zag-shaped joint ligands, dpt (2,5-bis(diphenylphosphoryl)thiophene), to enhance the photosensitized luminescence supported by the inter-LCT (Fig. 7e ${ }^{48}$. They exhibit a high intrinsic emission quantum yield $(75 \%)$ due to their asymmetrical and low-vibrational coordination structures around the $\mathrm{Eu}(\mathrm{III})$ ions. The characteristic alternative zig-zag orientation of the substituents also contributes to the dramatically high energy transfer efficiencies supported by the inter-LCT of up to $80 \%$ in the solid state. The high $\eta_{\text {sens }}$ might be due to the formation of inter-LCT states induced by the densely packed zig-zag orientation. We estimated the dipole moment $D$ of the bridging ligands by DFT calculations (B3LYP/6-31G (d)) based on the CIF data of their X-ray single-crystal analysis data. Compared to the linear-type $\mathrm{Eu}(\mathrm{III})$ coordination polymer [Eu (hfa) ${ }_{3}(\text { dpbp) }]_{n} \quad$ (Fig. $\quad 7 f$, dpbp: 4,4'-bis(diphenylphosphoryl)-1,1'-biphenyl, $D=0.0005$ ), the zig-zag-type Eu (III) coordination polymers show large $D$ values $(1.1664$ for $\left[\mathrm{Eu}(\mathrm{hfa})_{3}(\mathrm{dpt})\right]_{n}$ and 4.2992 for $\left[\mathrm{Eu}(\mathrm{hfa})_{3}(\mathrm{dpe}-\right.$ dot) $]_{n}$ (dpedot: 2,5-bis(diphenylphosphoryl)ethylenedioxythiophene). The polar character of the bridging ligands 

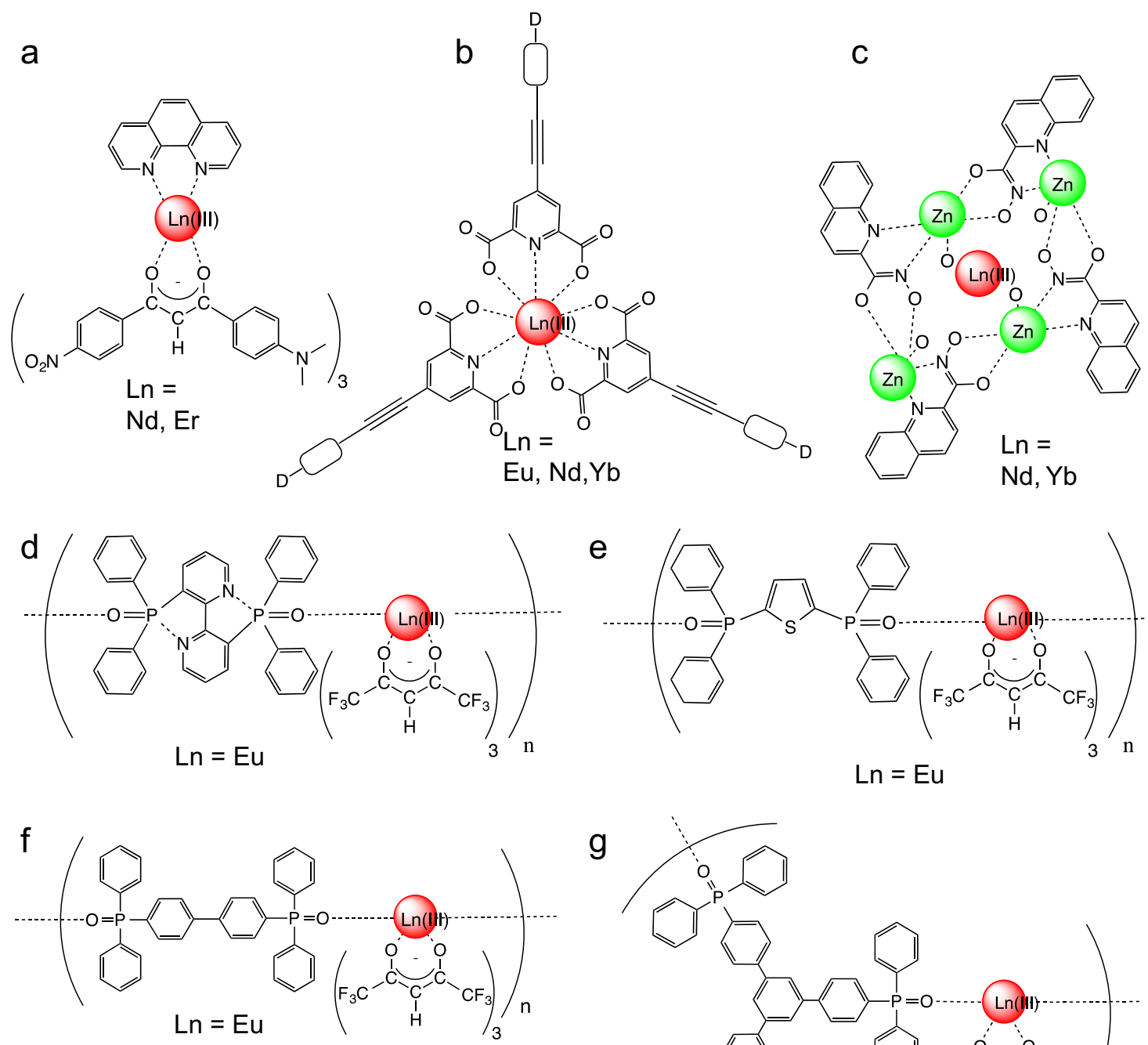

g

$\mathrm{Ln}=\mathrm{Eu}$

h

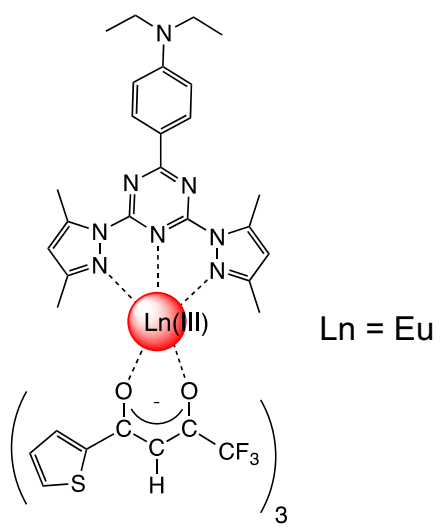

g

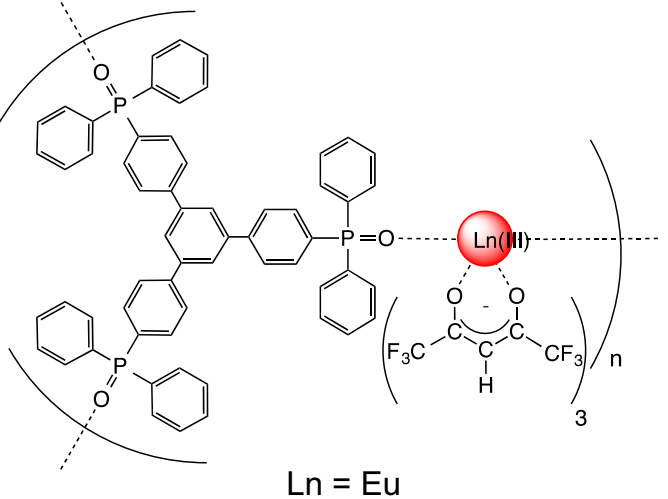

Fig. 7 Chemical structures of lanthanide(III) complexes with photosensitized luminescence accelerated with CT bands

resulted in a characteristic alternative orientation of the inter-polymer or intra-polymer chains.

We also reported the strong photosensitized luminescence of a three-dimensional $\mathrm{Eu}(\mathrm{III})$ coordination polymer with an attached triangular spacer ligand, tppb (1,3,5-tris(4-diphenylphosphorylphenyl)benzene). The intrinsic and photosensitized emission quantum yields, $\Phi_{\mathrm{f}-\mathrm{f}}$ and $\Phi_{\pi-\pi^{*}}$, were calculated to be $82 \%$, and $64 \%$, 
respectively. The energy transfer efficiency, $\eta_{\text {sens }}$, was calculated to be $78 \%$, which is similar to that of the zigzag-shaped $\mathrm{Eu}(\mathrm{III})$ coordination polymers (Fig. $7 \mathrm{~g})^{49}$.

The LMCT bands of some $\mathrm{Eu}(\mathrm{III})$ complexes are observed at approximately $400 \mathrm{~nm}$. The LMCT band in a lanthanide(III) complex does not generate effective energy transfer. In $\mathrm{Eu}(\mathrm{III})$ complexes, the LMCT band from the $\mathrm{S}_{0}$ state of the ligand to the $\mathrm{Eu}(\mathrm{III})$ ion leads to effective quenching of the excited $\mathrm{Eu}(\mathrm{III})$ complex $^{50-55}$. The results of the detailed analysis of quenching by the LMCT band using a dinuclear $\mathrm{Eu}(\mathrm{III})$ complex have been reported ${ }^{56,57}$. Studies on photosensitized luminescence assisted by the LMCT band of lanthanide(III) complexes are limited; however, the photosensitized luminescence of some $\mathrm{Eu}$ (III) and Sm(III) complexes assisted by the LMCT bands have been reported as specific examples (Fig. $7 \mathrm{~h})^{58-60}$.

Generally, the standard electrode reduction potential of $\mathrm{Eu}(\mathrm{III})$ in water is estimated to be $-0.35 \mathrm{~V}$, which is smoothly transformed to meta-stable $\mathrm{Eu}(\mathrm{II})$ ions. For this reason, the excitation of the LMCT band in an $\mathrm{Eu}(\mathrm{III})$ complex promotes the intramolecular photoreduction of the $\mathrm{Eu}(\mathrm{III})$ ion and the formation of the $\mathrm{Eu}(\mathrm{II})$ ion $^{61,62}$. Using the photoreduction technique, we also observed the decomposition of $\mathrm{Eu}(\mathrm{III})$ complexes and the formation of $\mathrm{Eu}$ (II) compounds ( $\mathrm{EuO}$ and $\mathrm{EuS}$ nanoparticles) under the condition of LMCT band excitation $^{63-65}$. Decomposition processes using gas-phase and laser-assisted MOCVD techniques have also been reported $^{66,67}$.

The effective photosensitized luminescence of lanthanide(III) complexes is assisted by the presence of (1) an intra-LCT band formed by the introduction of donor parts in the organic ligands and (2) an inter-LCT band formed by the steric strain in the organic ligands in the crystals. The design of intra-LCT and inter-LCT is a promising strategy for developing a strong luminescent lanthanide(III) complex.

\section{Photosensitized luminescence from a metal complex}

\section{Light and transition metal complexes}

The photosensitized luminescence of lanthanide(III) complexes attached with metal complexes has been widely reported. There are three species of metal complexes for photosensitization: (1) light metal complexes, (2) transition metal complexes, and (3) lanthanide(III) complexes.

First, the photosensitized luminescence of lanthanide (III) complexes excited at the transition bands in light metal complexes are explained. $\mathrm{Xu}$ et al. ${ }^{68}$ reported the photosensitized luminescence of polynuclear Eu(III), Nd (III), and $\mathrm{Yb}(\mathrm{III})$ hfa complexes attached with three $\mathrm{Al}(\mathrm{III})$ quinolinate complexes (Fig. 8a). Aluminum (Al) is an element in family 13 (IIIA) in the periodic table. Al(III) quinolinate complexes are well known as green luminescent chromophores for EL devices ${ }^{69}$. The emission quantum yield of $\mathrm{Eu}(\mathrm{III})$ complexes with photosensitized $\mathrm{Al}(\mathrm{III})$ parts was estimated to be $6.1 \%$. Furthermore, Smith et al. ${ }^{70}$ reported the photosensitized luminescence of $\mathrm{Eu}(\mathrm{III})$ complexes with monodentate and bidentate boron complexes in diketonate ligands (Fig. 8b). Boron complexes with three aryl groups, triarylborons, are transformed by the presence of fluorine ions, resulting in the formation of a $\mathrm{B}-\mathrm{F}$ bond in the triarylboron unit. The formation of a $\mathrm{B}-\mathrm{F}$ compound in the triarylboron unit accelerates the photosensitized luminescence of the $\mathrm{Eu}$ (III) complex. $\mathrm{Eu}(\mathrm{III})$ complexes with monodentate and bidentate triarylboron units are sensitive to fluorine ions in liquid media.

Next, the photosensitized luminescence of lanthanide (III) complexes with transition metal complexes are introduced. Various types of transition metal complexes for the photosensitization of lanthanide(III) complexes have been reported. Among them, luminescent $\mathrm{Zn}$ (II), Ir (III), and $\mathrm{Ru}(\mathrm{II})$ complexes are generally used for the photosensitized luminescence of lanthanide(III) complexes.

The metal-to-ligand CT (MLCT) bands in Zn(II) complexes are observed in the UV region. The energy levels of their MLCT bands are higher than those of the emitting levels of $\mathrm{Tb}(\mathrm{III})$ and $\mathrm{Eu}(\mathrm{III})$ ions. The MLCT bands promote effective photosensitized energy transfer in $\mathrm{Zn}$ (II)-Ln(III) hybrid complexes. Dinuclear Zn(II)-Ln(III) complexes with Schiff base ligands show effective photosensitized luminescence (Fig. 8c) ${ }^{71-74}$. Luminescent polynuclear $\mathrm{Zn}(\mathrm{II})-\mathrm{Ln}(\mathrm{III})$ complexes with $\mathrm{Zn}$ (II) quinolinate, terpyridine, phenanthroline, and a Schiff base have also been reported (Fig. 8d) ${ }^{75-80}$. We synthesized an Eu (III) coordination polymer cross-linked with a $\mathrm{Zn}$ (II) complex as a joint ligand (Fig. 8e) ${ }^{81}$. The intrinsic emission quantum yield $\left(\Phi_{\mathrm{f}-\mathrm{f}}\right)$ was estimated to be $59 \%$.

Various types of lanthanide(III) complexes attached with $\operatorname{Ir}(\mathrm{III})$ complexes have also been reported (Fig. 8f ${ }^{82-}$ ${ }^{85}$. Generally, Ir(III) complexes show blue, green, and red luminescence at room temperature based on the MLCT transition bands. The MLCT transition of an $\operatorname{Ir}(\mathrm{III})$ complex leads to efficient luminescence with a highemission quantum yield ${ }^{86}$. The emission color of an $\operatorname{Ir}(\mathrm{III})$ complex is dependent on the energy level of the organic ligands. Blue and green luminescent $\operatorname{Ir}(\mathrm{III})$ complexes are used for the photosensitized luminescence of lanthanide (III) complexes. The effective photosensitization of a polynuclear $\mathrm{Ir}(\mathrm{III})-\mathrm{Eu}(\mathrm{III})$ complex has been reported. The emission quantum yield excited at the MLCT band is estimated to be $44 \%$ (Fig. $8 \mathrm{~g}$ ) ${ }^{84}$. Bian and Ward reported the photosensitized luminescence of red luminescent $\operatorname{Ir}(\mathrm{III})-\mathrm{Eu}(\mathrm{III})$ and green luminescent $\mathrm{Ir}(\mathrm{III})-\mathrm{Tb}(\mathrm{III})$ systems (Fig. 8h) ${ }^{87-90}$. 


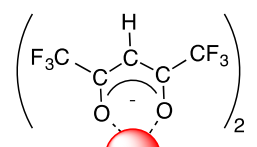

a

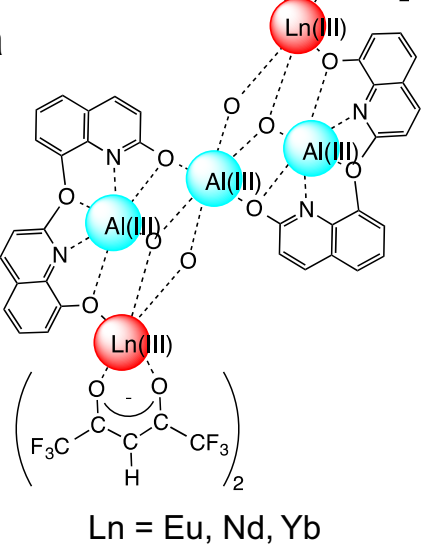

b

C

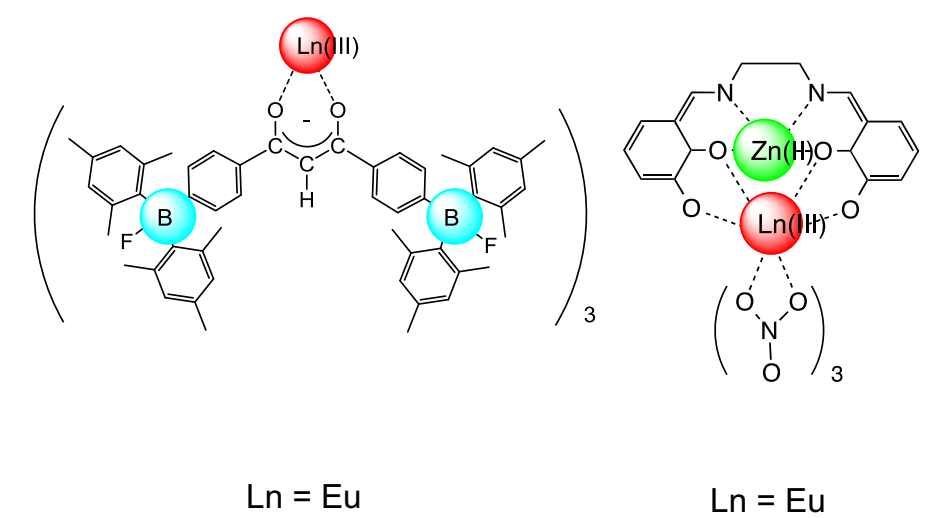

d

e

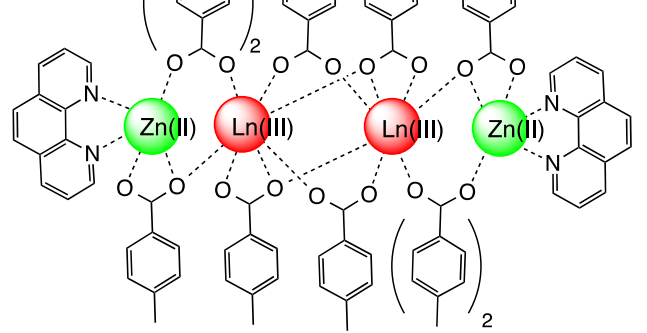

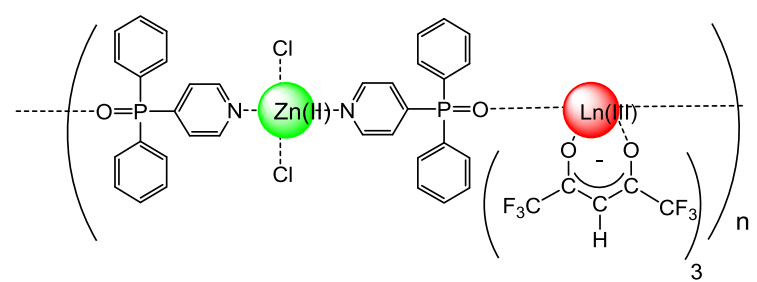
$\mathrm{Ln}=\mathrm{Tb}, \mathrm{Nd}, \mathrm{Ho}$

f

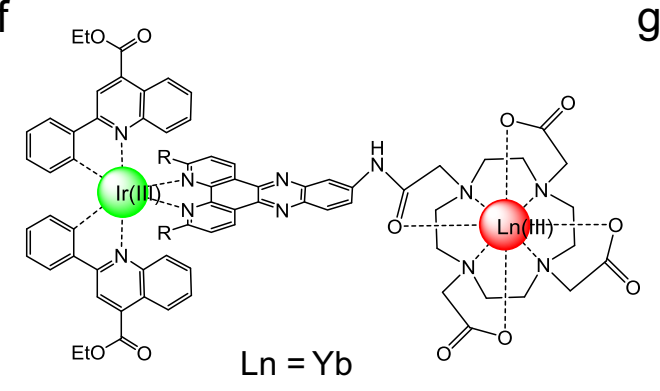

g $\mathrm{Ln}=\mathrm{Eu}$
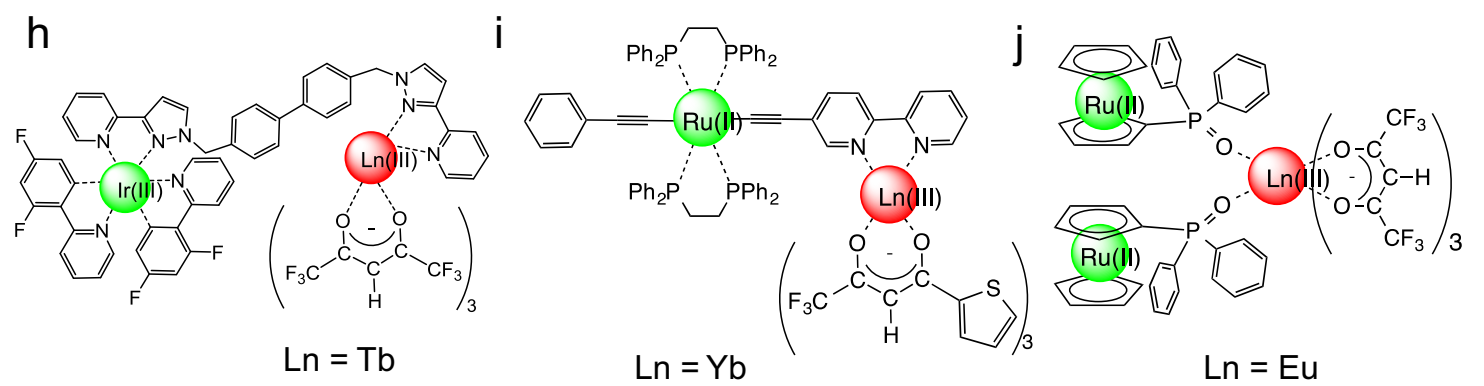

Fig. 8 Chemical structures of lanthanide(III) complexes with Al, B, Zn, Ir, and Ru complexes 
The $\mathrm{Ru}(\mathrm{II})-\mathrm{Ln}(\mathrm{III})$ complex is also a popular system for the photosensitized luminescence of a lanthanide (III) complex. Generally, the emission band of an $\mathrm{Ru}(\mathrm{II})$ complex is observed at approximately $600 \mathrm{~nm}$. The red luminescence of an $\mathrm{Ru}(\mathrm{II})$ complex is effective for the photosensitization of near-IR luminescence of $\mathrm{Yb}$ (III) and $\mathrm{Nd}(\mathrm{III})$ complexes. Gunnlaugsson, Charbonnière, and Faulkner ${ }^{91,92}$ reported the near-IR luminescence of $\mathrm{Ru}(\mathrm{II})-\mathrm{Ln}(\mathrm{III})(\mathrm{Ln}=\mathrm{Nd}(\mathrm{III})$ and $\mathrm{Yb}(\mathrm{III})$ ) complexes in water media. Rigaut and co-workers ${ }^{93}$ reported $\mathrm{Yb}(\mathrm{III})$ complexes with a carbon-rich ruthenium antenna (Fig. 8i). Sun made a molecular architecture composed of $\mathrm{Ru}(\mathrm{II})$ bipyridyl complexes and $\operatorname{Ln}(\mathrm{III})$ acetates $^{94}$. Furthermore, organometallic ruthenocene $\left[\mathrm{Ru}\left(\mathrm{C}_{5} \mathrm{H}_{5}\right)_{2}\right]$ exhibits a white color, and the MLCT band is located in the UV region. We reported luminescent $\mathrm{Eu}(\mathrm{III})$ complexes attached with ruthenocene units (Fig. 8j) ${ }^{95}$. Ward ${ }^{96}$ reviewed the energy transfer of $\mathrm{Ru}(\mathrm{II})-\mathrm{Ln}(\mathrm{III})$ complexes.

Photosensitized luminescence using $\operatorname{Re}-\mathrm{Ln}(\mathrm{III})^{92,97}$, $\mathrm{Pt}-\mathrm{Ln}(\mathrm{III})^{98-100}, \quad \mathrm{Au}-\mathrm{Ln}(\mathrm{III})^{99,101}, \quad \mathrm{Ag}-\mathrm{Ln}(\mathrm{III})^{99,102}$, $\mathrm{Cd}-\mathrm{Ln}(\mathrm{III})^{103,104}$, and Os-Ln(III) ${ }^{96}$ systems has also been reported. In general, their CT (MLCT, LMCT, metalmetal-to-ligand CT, etc.) bands of $\mathrm{Re}, \mathrm{Au}, \mathrm{Ag}, \mathrm{Cd}$, and $\mathrm{Os}$ complexes show emission in the vis region. From these photophysical findings, the near-IR luminescence of $\mathrm{Nd}$ (III) and $\mathrm{Yb}(\mathrm{III})$ complexes with $\mathrm{Re}, \mathrm{Au}, \mathrm{Ag}, \mathrm{Cd}$, and $\mathrm{Os}$ complexes has been described.

\section{Active use of energy transfer in lanthanide complexes}

The energy transfer between the $\mathrm{Ln}(\mathrm{III})$ ions in polynuclear lanthanide(III) complexes and the clusters leads to characteristic emission properties, energy migration, temperature-dependent luminescence, multi-color component emission (triple luminescence), and upconversion luminescence. In this section, characteristic luminescence related to energy transfer between $\operatorname{Ln}(\mathrm{III})$ ions is described.

We reported the effective energy migration of a $\mathrm{Tb}(\mathrm{III})$ cluster composed of $9 \mathrm{~Tb}(\mathrm{III})$ ions and 16 salicylate ligands (Fig. 5f) ${ }^{105}$. The energy migration in a $\mathrm{Tb}(\mathrm{III})$ nonanuclear cluster leads to a decrease in the energy back transfer from the excited $\mathrm{Tb}(\mathrm{III})$ ions to the $\mathrm{T}_{1}$ state of the ligands, resulting in thermal relaxation and a decrease in the emission quantum yield. The kinetics analysis of the temperature dependence of emission lifetimes using $\mathrm{Tb}$ (III)/Gd(III) mixed nonanuclear clusters showed that the energy transfer between $\mathrm{Tb}$ (III) ions competes with the energy back transfer. The results provide a new molecular design strategy to improve the efficiency of the luminescence of lanthanide(III) complexes.

We also reported the temperature-dependent luminescence of lanthanide coordination polymers composed of $\mathrm{Tb}(\mathrm{III})$ and $\mathrm{Eu}(\mathrm{III})$ complexes, $\left[\mathrm{Tb}, \mathrm{Eu}(\mathrm{hfa})_{3}(\mathrm{dpbp})\right]_{n}(\mathrm{~Tb}$ $(\mathrm{III}) / \mathrm{Eu}(\mathrm{III})=99)$, for temperature sensing between 200 and $500 \mathrm{~K}$ (Fig. 9) ${ }^{106}$. The remarkable thermosensitive properties of $\left[\mathrm{Tb}_{0.99} \mathrm{Eu}_{0.01}(\mathrm{hfa})_{3}(\mathrm{dpbp})\right]_{n}$ are influenced by the energy transfer efficiency between the $\mathrm{Tb}(\mathrm{III})$ and $\mathrm{Eu}$ (III) ions in the coordination polymer matrix. The energy transfer efficiency between the $\mathrm{Tb}(\mathrm{III})$ and $\mathrm{Eu}(\mathrm{III})$ ions is estimated by

$$
\eta_{T b-E u}=1-\left(\tau_{o b s} / \tau_{T b}\right),
$$

where $\tau_{\mathrm{obs}}$ and $\tau_{\mathrm{Tb}}$ are the emission lifetimes of [Tb,Eu $\left.(\mathrm{hfa})_{3}(\mathrm{dpbp})\right]_{n}$ and $\left[\mathrm{Tb}(\mathrm{hfa})_{3}(\mathrm{dpbp})\right]_{n}$, respectively. Using this equation, the values of $\eta_{\mathrm{Tb}-\mathrm{Eu}}$ at $200,250,275$, and $300 \mathrm{~K}$ are estimated to be $1 \%, 19 \%, 26 \%$, and $38 \%$, respectively. The value of $\eta_{\mathrm{Tb}-\mathrm{Eu}}$ increases with the increase in temperature. We observed the temperaturedependent energy transfer efficiency of a [Tb,Eu $\left.(\mathrm{hfa})_{3}(\mathrm{dpbp})\right]_{n}$ crystal. Previously, the energy transfer from $\mathrm{Tb}$ (III) ions to $\mathrm{Eu}$ (III) ions was studied by using mononuclear and dinuclear lanthanide complexes in homogeneous organic and aqueous media. We consider that the energy transfer mechanism of $\left[\mathrm{Tb}, \mathrm{Eu}(\mathrm{hfa})_{3}(\mathrm{dpbp})\right]_{n}$ is different from those in previously reported homogeneous systems in solution. Regarding the energy transfer mechanism of $\left[\mathrm{Tb}, \mathrm{Eu}(\mathrm{hfa})_{3}(\mathrm{dpbp})\right]_{n}$, Hatanaka et al. ${ }^{107}$ and Hatanaka and Morokuma ${ }^{108}$ first reported the presence of the activation energy on organic joint ligands determined by quantum calculations. A collaborative study using quantum calculations as additional experiments is expected to open up a new field of photophysical theory of the energy transfer process. The development of thermosensitive luminophores using the energy transfer in $\operatorname{Ln}(\mathrm{III})$ polynuclear complexes, coordination polymers and clusters has also been explored ${ }^{109-118}$.

The multi-color component emission (triple luminescence) of a photosensitized lanthanide(III) system using $\mathrm{Eu}(\mathrm{III}) / \mathrm{Tb}(\mathrm{III}) / \mathrm{Gd}(\mathrm{III}) \mathrm{MOF}$ (metal-organic framework) systems ${ }^{119-121}$ cross-linked with aromatic joint parts containing pyridyl, sulfonyl, and/or carbonyl groups has been reported. The multi-color emission is composed of a red luminescent $\mathrm{Eu}(\mathrm{III})$ complex, a green luminescent $\mathrm{Tb}$ (III) complex, and a blue luminescent ligand (phosphorescence) in the Gd(III) parts (the emitting level of the $\mathrm{Gd}$ (III) ion is higher than the $\mathrm{T}_{1}$ state of the organic ligands). The triple component emission of the $\mathrm{Eu}(\mathrm{III}) / \mathrm{Tb}(\mathrm{III}) / \mathrm{Gd}$ (III) MOF system plays a role in precise color tuning for the naked eye and the creation of white lighting. $\mathrm{Eu}(\mathrm{III}) /$ $\mathrm{Tb}(\mathrm{III}) / \mathrm{La}, \mathrm{Eu}(\mathrm{III}) / \mathrm{Tb}(\mathrm{III}) / \mathrm{Gd}(\mathrm{III}) / \mathrm{Zn}(\mathrm{II})$, and $\mathrm{Eu}(\mathrm{III}) / \mathrm{Tb}$ (III)/ligand MOF systems have also been reported ${ }^{122-124}$.

In the field of inorganic material science and engineering, the upconversion luminescence of lanthanide compounds is well known as a wavelength conversion phenomenon from lower to higher photon energy. The upconversion luminescence is based on the energy transfer between metal and lanthanide ions ${ }^{125}$. In 2011, Piguet and co-workers ${ }^{126}$ reported the first example of the 

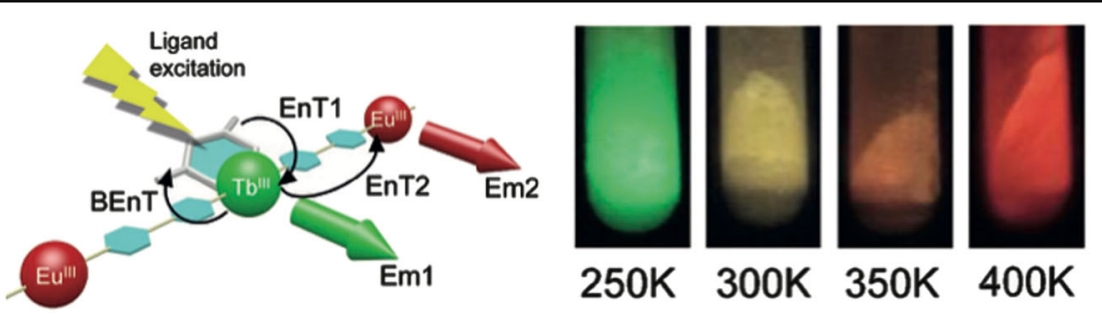

Fig. 9 Temperature-dependent color changing properties of a Tb(III)/Eu(III) mixed coordination polymer $\left[\mathrm{Tb}, \mathrm{Eu}(\mathrm{hfa})_{3}(\mathrm{dpbp})\right]_{n}$. Color pictures of $\left[\mathrm{Tb}_{0.99} \mathrm{Eu}_{0.01}(\mathrm{hfa})_{3}(\mathrm{dpbp})\right]_{n}$ under UV $(365 \mathrm{~nm})$ irradiation, which show brilliant green, yellow, orange, and red emission. Reprinted with permission from Iki et al ${ }^{106}$ Copyright 2013 Wiley-VCH Verlag GmbH \& Co

upconversion luminescence of an $\mathrm{Er}(\mathrm{III})$ helical complex with two $\mathrm{Cr}$ (III) units (Fig. 10a). The result of detailed analysis of the $\operatorname{Er}$ (III) helical complex with two $\mathrm{Cr}$ (III) units has also been reported ${ }^{127}$. Charbonnière and coworkers ${ }^{128,129}$ reported the upconversion luminescence of a dinuclear Er(III) complex (Fig 10b) and a polynuclear Tb (III)/Yb(III) complex. Faulkner and co-workers ${ }^{130}$ reported the upconversion luminescence of a mononuclear Tm (III) complex in solution. A hybrid system composed of $\mathrm{Yb}(\mathrm{III}) / \mathrm{Tm}_{2} \mathrm{O}_{3}$ interfacial coordination nanoparticles was also reported (Fig. 10c) ${ }^{131}$. Lanthanide coordination compounds are expected to play an important role in the molecular-level analysis of upconversion luminescence.

The photosensitized luminescence from neighboring lanthanide(III) ions in a coordination system promotes not only the enhancement of the emission intensity but also the characteristic energy migration luminescence, temperature-dependent luminescence, multi-color component emission (triple luminescence), and upconversion luminescence. The photosensitized luminescence from activated lanthanide ions is a key phenomenon for the creation of new advanced luminescent materials in the future.

\section{Electrosensitized luminescence}

Lanthanide(III) complexes on glass electrodes or semiconductor crystals are expected to be useful for applications in display devices, such as organo-EL or electrochemically luminescent devices, light-emitting diode (LED) tip devices, and photovoltaic polymer memories. Kido et al. ${ }^{132}$ was first to report the EL of a Tb (III) acetylacetonate complex in EL devices (Fig. 11a). We also reported the near-IR EL of an $\mathrm{Nd}(\mathrm{III})$ complex $\left(\right.$ Fig. 11b) ${ }^{133}$. Kido and Okamoto ${ }^{5}$, de Bettencourt-Dias ${ }^{6}$ and $\mathrm{Xu}$ et al. ${ }^{134}$ have written reviews of lanthanide complex-based emitting materials in the field of LEDs. Wang et al. ${ }^{135}$ also reported the EL of Eu(III) complexes with hfa and phosphine monodentate oxide ligands. The EL luminance was estimated to be $>90 \mathrm{~cd} \mathrm{~m}^{-2}$.

The performance of EL devices depends on the molecular structure of the lanthanide(III) coordination compounds. Recently, thermo-stable polymer materials attached with lanthanide complexes have been synthesized (Fig. 11c) ${ }^{136}$. The glass transition temperature and EL luminance were estimated to be $220^{\circ} \mathrm{C}$ and $149 \mathrm{~cd}$ $\mathrm{m}^{-2}$, respectively. We also reported $\mathrm{Eu}(\mathrm{III})$ coordination nanoparticles on glass electrodes for EL devices ${ }^{137}$. The thermostability of a luminescent lanthanide complex is one of important factors for the fabrication of EL devices.

The characteristic EL performance has been reported. White EL using an Eu(III) coordination polymer has also been reported (Fig. 11d) $)^{138}$. Bari and co-workers ${ }^{139}$ showed effective circularly polarized EL using a chiral $\mathrm{Eu}$ (III) complex (Fig. 11e). Zhang and co-workers ${ }^{140}$ reported high-performance EL combined with an Ir(III) complex, a $\mathrm{Tb}(\mathrm{III})$ complex and a $\mathrm{Gd}(\mathrm{III})$ complex in devices $\left(145,071 \mathrm{~cd} \mathrm{~m}^{-2}\right)$.

Various types of organic EL devices using organic molecules and transition metal complexes have been extensively studied. Highly efficient Ir(III) complexes and the characteristic TADF (thermally activated delayed fluorescence) of organic dyes have been studied for the fabrication of bright luminescent EL devices ${ }^{141-144}$. The EL properties of lanthanide(III) complexes are greatly different from those of organic molecules and transition metal complexes. The $4 \mathrm{f}-4 \mathrm{f}$ emissions of lanthanide(III) complexes play an important role in the design of monochromatic luminescent materials for display devices (narrow emission band: FWHM $<10 \mathrm{~nm})^{145}$, although EL devices using organic dye and transition metal complexes show broad emission spectra (FWHM $>50 \mathrm{~nm}$ ). At present, the luminance of EL devices using lanthanide complexes is smaller than that of EL devices using organic molecules and transition metal complexes. However, lanthanide(III) complexes with characteristic EL are expected to be key materials for future displays.

\section{Mechanosensitized luminescence}

The luminescence generated upon grinding solid materials is called triboluminescence (tribo-sensitized luminescence). In the seventeenth century, it was first noted by Francis Bacon who mentioned that "It is well 
a

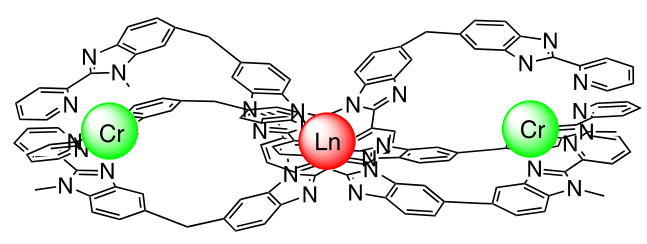

$\mathrm{Ln}=\mathrm{Er}$ b

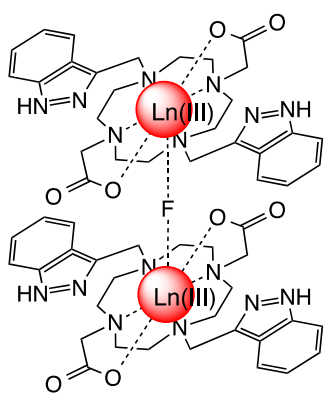

$\mathrm{Ln}=\mathrm{Er}$
C

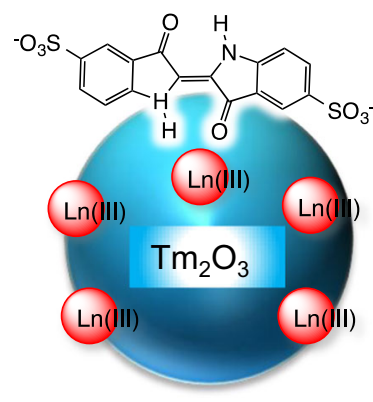

$\mathrm{Ln}=\mathrm{Yb}$
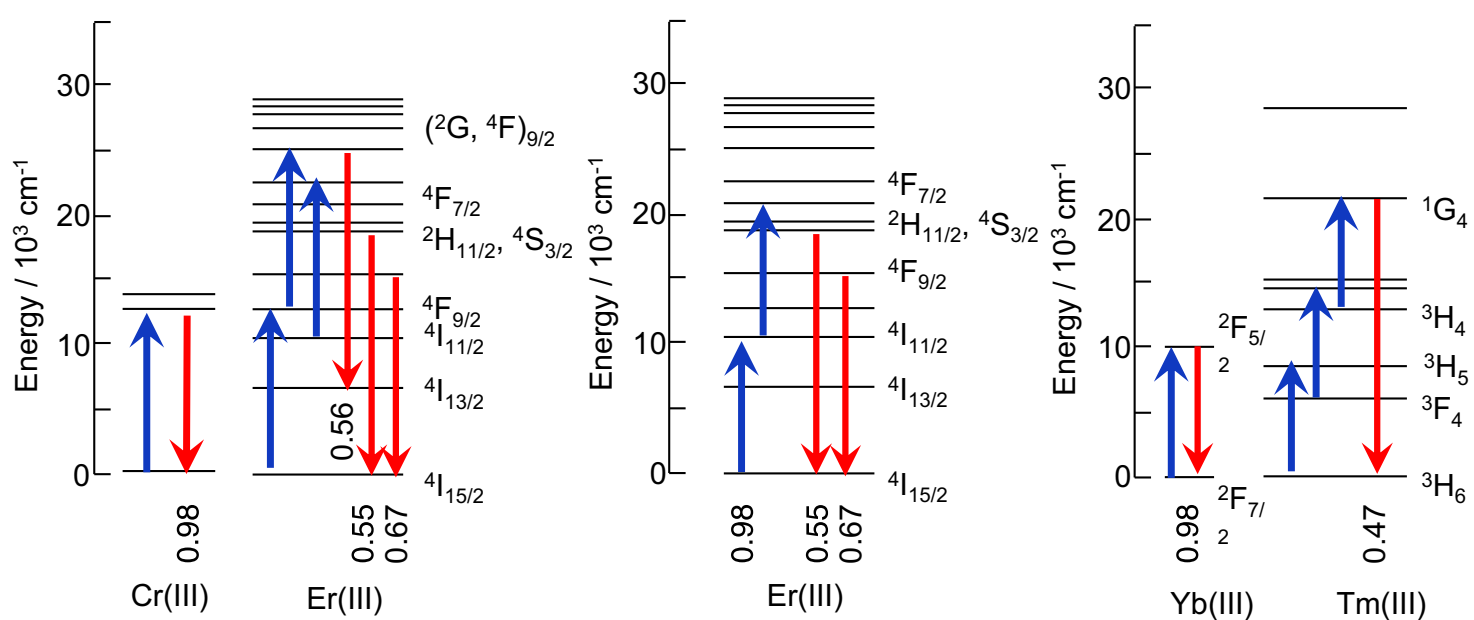

Fig. 10 Chemical structures and upconversion energy diagram of lanthanide(III) complexes with upconversion luminescence

known that all sugar, whether candied or plain, if it be hard, will sparkle when broken or scraped in the dark." Triboluminescent materials, unlike well-known photoluminescence materials, have the advantage of emission without requiring a light source ${ }^{146-148}$. The fractureinduced luminescent properties of triboluminescent materials make them attractive for applications as structural damage sensors and pressure sensors and for advanced security marking techniques ${ }^{149-152}$.

Different types of materials that exhibit triboluminescence, such as organic crystals, polymers, and metal complexes, have been studied. The first example of triboluminescence using a lanthanide(III) complex was reported in 1966 (Fig. 12a) ${ }^{153}$. In 1987, Sweeting and Rheingold ${ }^{154}$ showed the importance of charge separation and recombination in solid state lanthanide(III) complexes. Some triboluminescence phenomena of lanthanide (III) complexes in crystals and polymer matrices have also been reported (Fig. 12b, c) ${ }^{155-166}$. Chen et al. ${ }^{167}$ suggested that strongly luminescent lanthanide coordination polymer crystals with non-centrosymmetric structures are expected to show efficient triboluminescence because of the generation of opposite electric charges on opposing faces of cracks perpendicular to their polar axes. Charge recombination on the crystal faces produces triboluminescence. From this point, triboluminescence is regarded as electrosensitized luminescence.

Eliseeva et al. $^{168}$ reported triboluminescence from a lanthanide coordination polymer composed of lanthanide (III) hfa complexes and 1,4-dimethylterephthalate joint ligands (Fig. 12d). We also reported strong triboluminescence from an $\mathrm{Eu}(\mathrm{III})$ coordination polymer with phosphine oxide joint ligands, $\left[\mathrm{Eu}(\mathrm{hfa})_{3} \mathrm{bipypo}_{n}\right.$ (Fig. $7 \mathrm{~d})^{47}$. The $\mathrm{Eu}(\mathrm{III})$ coordination polymer with a specific coordination structure of low-vibrational frequency and coordination networks exhibits intense triboluminescence upon breaking, which is clearly observed even at ambient temperatures in daylight (Fig. 13). The triboluminescence of a supramolecular lanthanide(III) coordination system has also been reported (Fig. 12e) ${ }^{169}$.

Triboluminescence-active compounds are known to show photoluminescence as well. Triboluminescence and photoluminescence occur from distinct stimuli, namely, grinding and photoirradiation, respectively; however, their spectra usually exhibit similar profiles. The relationship 

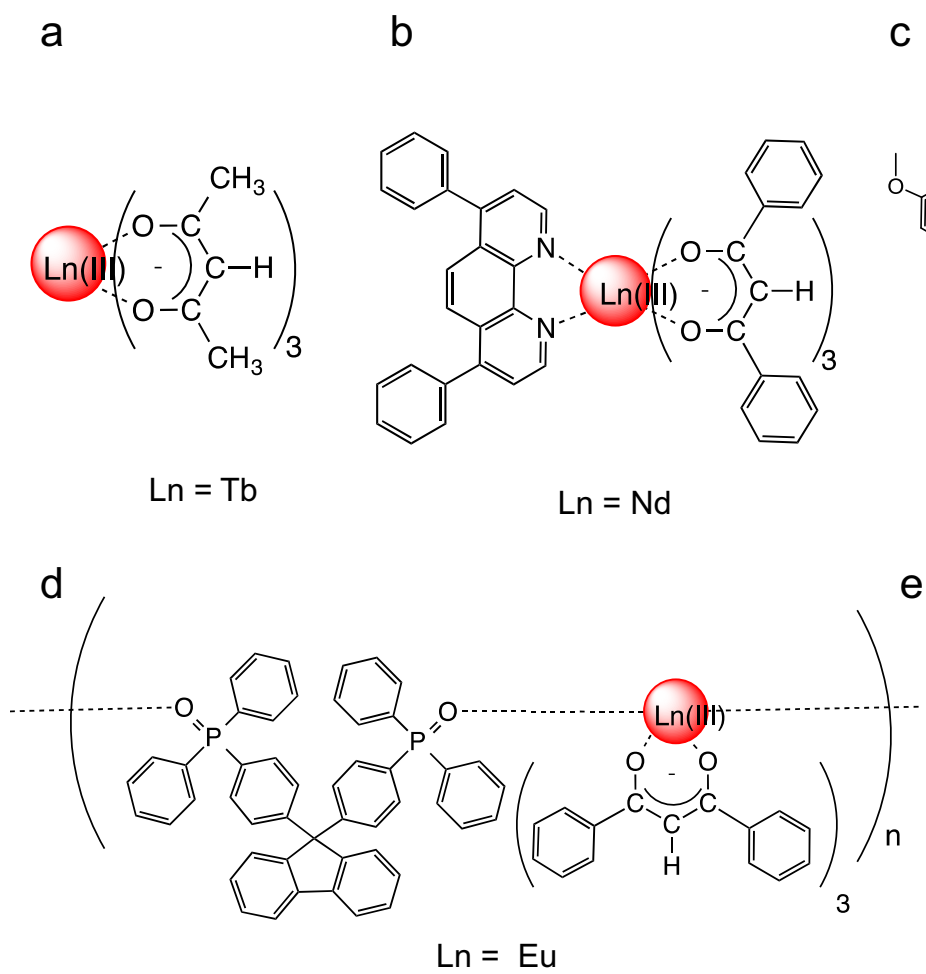

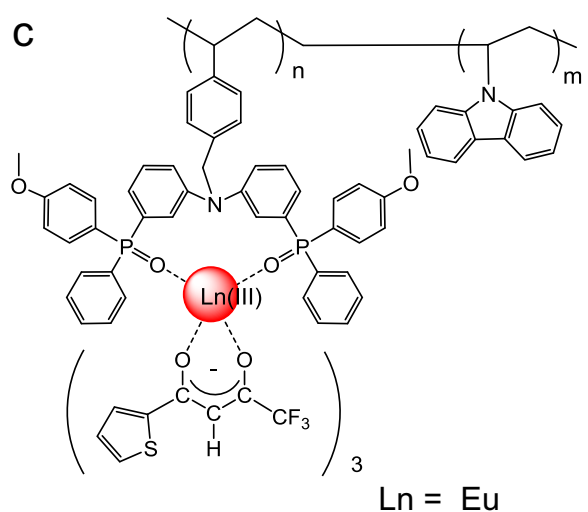

e

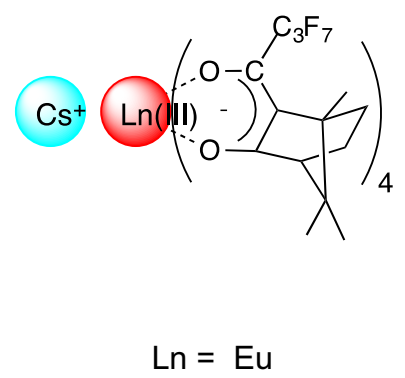

Fig. 11 Chemical structures of electroluminescent lanthanide(III) complexes

between triboluminescence and photoluminescence is still being discussed from a scientific point of view.

Reddy and co-workers ${ }^{156}$ recently demonstrated bright red triboluminescence and photoluminescence of $[\mathrm{Eu}$ $\left.(\mathrm{DPPF})_{3}(\mathrm{DDXPO})\right] \quad(\mathrm{DPPF}=1$-(4-(diphenylphosphino) phenyl)-4,4,5,5,5-pentafluoropentane-1,3-dione, DDXPO $=4,5$-bis(diphenylphosphino)-9,9-dimethylxanthene oxide). They also reported a slight decrease in the triboluminescence intensity when dispersed in PMMA films compared with that in the solid state. Teotonio et al. ${ }^{170}$ and Mikhalyova et al. ${ }^{171}$ suggested the possibility of triboluminescent energy transfer using lanthanide(III) complexes. Based on the difference between photoluminescence and triboluminescence properties, we discussed the spectral difference using a polar furan-linked $\mathrm{Tb}(\mathrm{III}) / \mathrm{Eu}(\mathrm{III})$ mixed coordination polymer with strong triboluminscence, $[\mathrm{Tb} /$ $\left.\left.\mathrm{Eu}(\mathrm{hfa})_{3} \mathrm{dpf}\right]\right]_{n} \quad$ (dpf: 2,5-bis(diphenylphosphoryl)furan) (Fig. 12f $)^{172}$. The Tb and Eu units in $\left[\mathrm{Tb} / \mathrm{Eu}(\mathrm{hfa})_{3}(\mathrm{dpf})\right]_{n}$ show strong photosensitized luminescence. The intrinsic emission quantum yield and energy transfer efficiency of the $\mathrm{Eu}(\mathrm{III})$ unit $\left[\mathrm{Eu}(\mathrm{hfa})_{3}(\mathrm{dpf})\right]_{n}$ are estimated to be $73 \%$ and $88 \%$, respectively. The intrinsic emission quantum yield and energy transfer efficiency of the $\mathrm{Tb}(\mathrm{III})$ units [ $\mathrm{Tb}$ $\left.(\mathrm{hfa})_{3}(\mathrm{dpf})\right]_{n}$ is also calculated to be $88 \%$ and $45 \%$, respectively. By using a $\mathrm{Tb}(\mathrm{III}) / \mathrm{Eu}(\mathrm{III})$ mixed coordination polymer $\left[\mathrm{Tb} / \mathrm{Eu}(\mathrm{hfa})_{3}(\mathrm{dpf})\right]_{n}$, we successfully observed a drastic spectral difference between the triboluminescence and photoluminescence. Based on the results, we consider the triboluminescence of the lanthanide(III) coordination compounds to be responsible for both the ligand excitation and direct $\operatorname{Ln}(\mathrm{III})$ excitation, unlike the selective excitation with specific wavelengths (for example, $\lambda_{\mathrm{ex}}=380 \mathrm{~nm}$ ) in photoluminescence. We also assume that the $\mathrm{Tb}(\mathrm{III})$-to-Eu (III) energy transfer occurs in both triboluminescence and photoluminescence with the same efficiency and that it is not responsible for the drastic color difference between the triboluminescence and photoluminescence.

Quantitative estimation of the triboluminescence efficiency is important to clarify the mechanism of triboluminescence and to develop strong triboluminescent materials. Generally, the drop-tower method is used to estimate the triboluminescence efficiency ${ }^{173-175}$. However, it is difficult to use the drop-tower method as a quantitative estimation (for calculations of the radiative and non-radiative rate constants). The development of a quantitative estimation method is needed to advance the field of triboluminescent material science. We developed a method to quantitatively estimate the triboluminescence using shockwave laser irradiation. The value of $k_{\mathrm{nr}}$ for triboluminescence is four times larger than that for photoluminescence in $\left[\mathrm{Eu}_{3}(\mathrm{hfa})_{9}(\mathrm{tppb})_{2}\right]_{n}$ crystals $(\mathrm{tppb}=$ tris (4-diphenylphosphorylphenyl)benzene) (Fig. $7 \mathrm{~g})^{49}$. These results indicate that the mechanical crushing of molecular crystals leads to an enhanced non-radiative transition in 

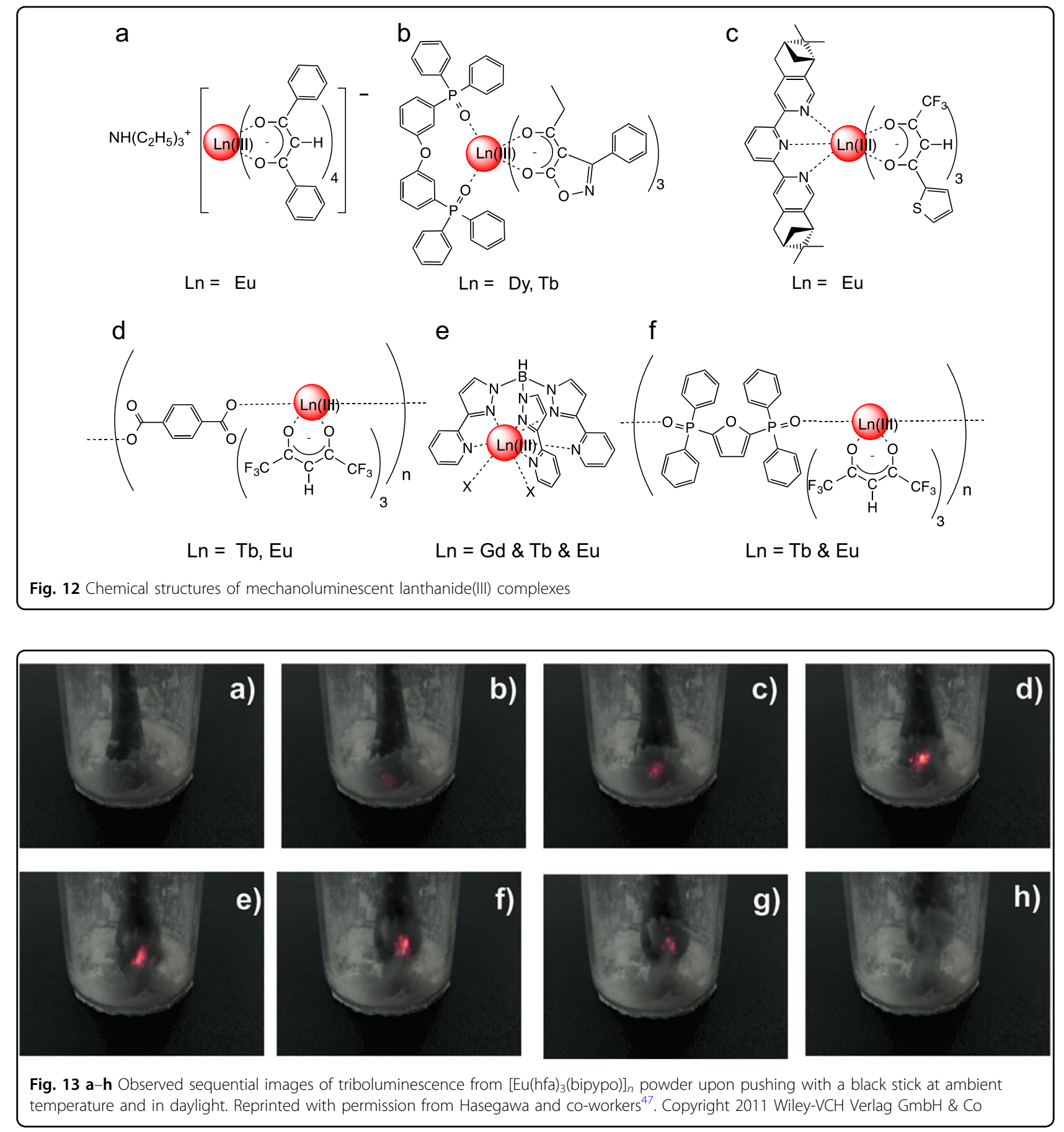

the quantum process. The shockwave irradiation is considered to promote the effective mechanical crushing of organic crystals and the formation of an excited state of the ligands.

A highly photosensitized luminescence efficiency in $\mathrm{Eu}$ (III) coordination compounds should be the key to observing triboluminescence. The effective molecular design and a suitable experimental analysis method for triboluminescent lanthanide(III) coordination compounds are expected to open a research pathway between coordination chemistry, materials chemistry, and photophysical chemistry.

\section{SUMMARY AND OUTLOOK}

The photo and electrosensitized luminescence of lanthanide(III) complexes can be manipulated by the ligand design. The luminescence of lanthanide(III) complexes can be realized and enhanced by designing ligands that coordinate to the lanthanide(III) ions. 
In the section on photosensitized luminescence, the importance of two factors, (1) the control of the $T_{1}$ state of the ligand and (2) the presence of intra-LCT and interLCT, was explained. These ligand designs lead to the development of a strong luminescent lanthanide(III) complex. The energy transfer processes from neighboring light metal, transition metal, and lanthanide(III) complexes were also described. The characteristic energy migration, temperature-dependent luminescence, multicolor luminescence, and upconversion luminescence for polynuclear lanthanide(III) complexes, clusters, coordination polymers and nanoparticles are expected to lead to the development of new molecular materials for photonic and opto-electronic devices.

We then described electrosensitized luminescence (EL) and mechanosensitized luminescence (triboluminescence) as electric field sensitization phenomena. EL using lanthanide(III) complexes can provide highly pure green and red luminescence with a narrow FWHM, which is fundamental toward the fabrication of full-color display devices. Invisible near-IR EL can also be achieved by a lanthanide(III) complex for industrial security applications. These characteristic EL properties of lanthanide(III) complexes are greatly different from those of corresponding organic and transition metal complexes. The construction of novel lanthanide complexes with efficient carrier injection is required for the development of EL materials. The study of the triboluminescence of molecular crystals started in the seventeenth century; however, the mechanism of triboluminescence has still not been clarified. Determination of the excited state concentrations is required to gain a more complete understanding of the triboluminescence mechanism. The study of the triboluminescence of lanthanide(III) complexes is expected to open up a new research avenue in the field of material science.

In this review, we introduced different molecular designs for the enhancement of the photosensitized luminescence properties of lanthanide(III) complexes. The emission quantum efficiency of a lanthanide(III) complex is also dependent on its coordination geometry and vibrational structure. We reported the importance of the radiative $k_{\mathrm{r}}$ constant depending on the lanthanide(III) coordination geometry ${ }^{176-185}$ and the non-radiative $k_{\mathrm{nr}}$ constant depending on the vibrational structure of the organic ligands ${ }^{186-197}$. Control of the $k_{\mathrm{r}}$ and $k_{\mathrm{nr}}$ constants in an excited lanthanide (III) complex is also important for the development of a strong luminescent lanthanide(III) complex.

Luminescent materials that include lanthanide(III) complexes are desirable for applications in novel organic lanthanide(III) devices, such as organic lasers, luminescent plastics, optical fibers, lasers, displays, lighting, wavelength converters for solar cells, and physical and biomedical sensors. The study of the photosensitized luminescence of lanthanide(III) complexes is expected to open research avenues among the fields of chemistry, physics, electronics, and materials science.

\section{Acknowledgements}

The author is very grateful to Prof. emeritus S. Yanagida (Osaka University), Prof. Y. Wada (Tokyo Institute of Technology), Prof. T. Kawai, Prof. T. Nakashima, (Nara Institute of Science and Technology), Dr. J. Yuasa (Tokyo University of Science), Prof. N. Nakashima (Osaka City University), Prof. T. Yamanaka (Osaka University), Prof. K. Murakoshi, Prof. M. Kato, Prof. H. Ito, Prof. Y. Hinatsu, Prof. H. Koizumi, Dr. A. Kobayashi, Dr. T. Seki, Dr. Y. Doi (Hokkaido University), Prof. K. Tanaka, Prof. K. Fujita (Kyoto University), Prof. P. O'Brien (University of Manchester), Prof. T.

Asahi (Ehime University), Dr. K. Nakamura (Chiba University), Dr. T. Nakagawa (Yokohama National University), Dr. Y. Kuramochi (Tokyo Institute of Technology), Dr. T. Harada (Shimane University), Prof. K. Fushimi (Hokkaido University) for their collaboration, measurements, and helpful comments. I would also like to thank the members of the Laboratory of Molecular Process Engineering at Osaka University, the Laboratory for Photonic Molecular Science at Nara Institute of Science and Technology, and the Laboratory of Advanced Materials Chemistry at Hokkaido University. This work was supported in part by Grants-in-Aid for Scientific Research on Innovative Areas of "New Polymeric Materials Based on Element-Blocks (No. 2401)" (24102012) of the Ministry of Education, Culture, Sports, Science and Technology (MEXT) of Japan.

\section{Conflict of interest}

The authors declare that they have no conflict of interest.

\section{Publisher's note}

Springer Nature remains neutral with regard to jurisdictional claims in published maps and institutional affiliations.

Received: 17 August 2017 Revised: 14 December 2017 Accepted: 1 January 2018.

Published online: 4 April 2018

\section{References}

1. Shriver, D. F. \& Atkins, P. W. Inorganic Chemistry 3rd edn, 320 (Oxford Univ. Oxford, 1999).

2. Hasegawa, Y., Wada, Y. \& Yanagida, S. Strategies for the design of luminescent lanthanide(III) complexes and their photonic applications. J. Photochem. Photobiol. C 5, 183-202 (2004).

3. Hasegawa, Y. Photofunctional lanthanoid complexes, coordination polymers, and nanocrystals for future photonic applications. Bull. Chem. Soc. Jpn. 87, 1029-1057 (2014)

4. Oyamada, T., Kawamura, Y., Koyama, T., Sasabe, H. \& Adachi, C. Formation of europium chelate complexes by vacuum co-deposition and their application in organic light-emitting diodes. Adv. Mater. 16, 1082-1086 (2004).

5. Kido, J. \& Okamoto, Y. Organo lanthanide metal complexes for electroluminescent materials. Chem. Rev. 102, 2357-2368 (2002).

6. Bettencourt-Dias, A. Lanthanide-based emitting materials in light-emitting diodes. Dalton Trans. 2229-2241 (2007).

7. Hasegawa, Y. \& Nakanishi, T. Luminescent lanthanide coordination polymers for photonic applications. RSC Adv. 5, 338-353 (2015).

8. Eliseeva, S. V. \& Bünzli, J.-C. G. Lanthanide luminescence for functional materials and bio-sciences. Chem. Soc. Rev. 39, 189-227 (2010).

9. Kataoka, H., Omagari, S., Nakanishi, T. \& Hasegawa, Y. Photo-degradation analysis of luminescent polymers with lanthanide complexes. J. Photopolym. Sci. Technol. 28, 247-254 (2015).

10. Kataoka, H. et al. Drastically improved durability and efficiency of silicon solar cells using hyper-stable lanthanide coordination polymer beads. Bull. Chem. Soc. Jpn. 89, 103-109 (2016).

11. Freed, S., Weissman, S. I., Fortress, F. E. \& Jacobson, H. F. lons of europium distributed between different configurations in homogeneous solutions. J. Chem. Phys. 7, 824-828 (1939).

12. Weissman, S. I. Intramolecular energy transfer the fluorescence of complexes of europium. J. Chem. Phys. 10, 214-217 (1942).

13. Yuster, P. \& Weissman, S. I. Effects of perturbations on phosphorescence: Luminescence of metal organic complexes. J. Chem. Phys. 17, 1182-1188 (1949). 
14. Hemmila, I. Luminescent lanthanide chelates-a way to more sensitive diagnostic methods. J. Alloy Compd. 225, 480-485 (1995).

15. Bünzli, J.-C. G. On the design of highly luminescent lanthanide complexes. Coord. Chem. Rev. 293-294, 19-47 (2015).

16. De Sá, G. F. et al. Spectroscopic properties and design of highly luminescent lanthanide coordination complexes. Coord. Chem. Rev. 196, 165-195 (2000)

17. Sato, S. \& Wada, M. Relations between intramolecular energy transfer efficiencies and triplet state energies in rare earth beta-diketone chelates. Bull. Chem. Soc. Jpn. 43, 1955-1962 (1970).

18. Latva, M. et al. Correlation between the lowest triplet state energy level of the ligand and lanthanide(III) luminescence quantum yield. J. Lumin. 75 149-169 (1997).

19. Shavaleev, N. M., Eliseeva, S. V., Scopelliti, R. \& Bünzli, J.-C. G. N-aryl chromophore ligands for bright europium luminescence. Inorg. Chem. 49, 3927-3936 (2010).

20. Shavaleev, N. M., Eliseeva, S. V., Scopelliti, R. \& Bünzli, J.-C. G. Designing simple tridentate ligands for highly luminescent europium complexes. Chem. Eur. J. 15, 10790-10802 (2009).

21. Shavaleev, N. M., Gumy, F., Scopelliti, R. \& Bünzli, J.-C. G. Highly luminescent homoleptic europium chelates. Inorg. Chem. 48, 5611-5613 (2009).

22. Archer, R. D., Chen, H. \& Thomson, L. C. Synthesis, characterization, and luminescence of europium(III) schiff-base complexes. Inorg. Chem. 37, 2089-2095 (1998).

23. Bünzli, J.-C. G. \& Eliseeva, S. V. In Lanthanide Luminescence: Photophysical, Analytical and Biological Aspects, Hänninen, P. \& Härmä, H., Eds., Vol. 7, 1-45 (Springer, Berlin, 2010).

24. Samuel, A. P. S., Xu, J. D. \& Raymond, K. N. Predicting efficient antenna ligands for Tb(III) emission. Inorg. Chem. 48, 687-698 (2009).

25. Nijegorodov, N., Ramachandran, V. \& Winkoun, D. P. The dependence of the absorption and fluorescence parameters, the intersystem crossing and internal conversion rate constants on the number of rings in polyacene molecules. Spectrochim. Acta Part A 53, 1813-1824 (1997).

26. Morgan, D. D., Warshawsky, D. \& Atkinson, T. The relationship between carcinogenic activities of polycyclic aromatic hydrocarbons and their singlet, triplet, and singlet-triplet splitting energies of phosphorescence lifetimes. Photochem. Photobiol. 25, 31-38 (1977).

27. Palewska, K. \& Chojnacki, H. Electronic spectra and luminescence properties of helicenes in crystalline matrices at 4.2K. Mol. Cryst. Liq. Cryst. 229, 31-36 (1993).

28. Kang, J.-S. et al. Neighbour-sensitized near-infrared emission of new Nd(iii) and Er(iii) complexes with 1-(anthracene-2-yl)-4,4,4-trifluoro-1,3-butanedione. N. J. Chem. 40, 9702-9710 (2016).

29. George, T. M., Varughese, S. \& Reddy, M. L. P. Near-infrared luminescence of $\mathrm{Nd}^{3+}$ and $\mathrm{Yb}^{3+}$ complexes using a polyfluorinated pyrene-based $\beta$-diketonate ligand. RSC Adv. 6, 69509-69520 (2016).

30. Divya, V. \& Reddy, M. L. P. Visible-light excited red emitting luminescent nanocomposites derived from $\mathrm{Eu}^{3+}$-phenathrene-based fluorinated $\beta$ diketonate complexes and multi-walled carbon nanotubes. J. Mater. Chem. C 1, 160-170 (2013).

31. Steemers, F. J., Verboom, W., Reinhoudt, D. N., van der Tol, E. B. \& Verhoeven, J. W. New sensitizer-modified calix[4]arenes enabling near-UV excitation of complexed luminescent lanthanide ions. J. Am. Chem. Soc. 117, 9408-9414 (1995).

32. Kitagawa, Y., Ohno, R., Nakanishi, T., Fushimi, K. \& Hasegawa, Y. Visible luminescent lanthanide ions and large $\pi$-conjugated ligand system shake hands. Phys. Chem. Chem. Phys. 18, 31012-31016 (2016).

33. Kitagawa, Y., Ohno, R., Nakanishi, T., Fushimi, K. \& Hasegawa, Y. Solventdependent dual-luminescence properties of europium complex with helical $\pi$-conjugated ligands. Photochem. Photobiol. Sci. 5, 683-689 (2017).

34. Lee, C. T., Yang, W. T. \& Parr, R. G. Development of the colle-salvetti correlation-energy formula into a functional of the electron-density. Phys. Rev. B 37, 785-789 (1988)

35. Becke, A. D. Density-functional thermochemistry. III. The role of exact exchange. J. Chem. Phys. 98, 5648-5652 (1993).

36. Zhang, B. et al. Systematic study of the luminescent europium-based nonanuclear clusters with modified 2-hydroxybenzophenone ligands. Inorg. Chem. 52, 13332-13340 (2013).

37. Omagari, S. et al. Effective photosensitized energy transfer of nonanuclear terbium cluster using methyl salicylate derivatives. J. Phys. Chem. A 119 1943-1947 (2015).
38. Lescop, C., Luneau, D., Bussière, G., Triest, H. \& Reber, C. Ligand-centered nearinfrared luminescence from lanthanide complexes with chelating nitronyl nitroxide free radicals. Inorg. Chem. 39, 3740-1947 (2000).

39. Kaizaki, S., Shirotani, D., Tsukahara, Y. \& Nakata, H. First observation of NIR $4 \mathrm{f}-4 \mathrm{f}$ luminescence through the energy transfer from the $\mathrm{SOMO} \pi^{*}$ doublet in nitronyl nitroxide radical lanthanide(III) complexes. Eur. J. Inorg. Chem. 2005, 3503-3505 (2005).

40. Kaizaki, S. Coordination effects of nitroxide radicals in transition metal and lanthanide complexes. Coord. Chem. Rev. 250, 1804-1818 (2006).

41. Nie, D. et al. Energy transfer pathways in the carbazole functionalized $\beta$ diketonate europium complex. N. J. Chem. 31, 1639-1646 (2007).

42. Shavaleev, N. M., Scopelliti, R., Gumy, F. \& Bünzli, J.-C. G. Visible-light excitation of infrared lanthanide luminescence via intra-ligand charge-transfer state in 1,3-diketonates containing push-pull chromophores. Eur. J. Inorg. Chem. 2008, 1523-1529 (2008).

43. D'Aleo, A. et al. Efficient sensitization of europium, ytterbium, and neodymium functionalized tris-dipicolinate lanthanide complexes through tunable charge-transfer excited states. Inorg. Chem. 47, 10258-10268 (2008).

44. Eliseeva, S. V. et al. Role of the ancillary ligand N,N-dimethylaminoethanol in the sensitization of Eulll and Tblll luminescence in dimeric $\beta$-diketonates. J. Phys. Chem. A 112, 3614-3626 (2008).

45. Puntus, L. N., Lyssenko, K. A., Antipin, M. Y. \& Bünzli, J.-C. Role of inner- and outer-sphere bonding in the sensitization of Eu-luminescence deciphered by combined analysis of experimental electron density distribution function and photophysical data. Inorg. Chem. 47, 11095-11107 (2008).

46. Trivedi, E. R. et al. Highly emitting near-infrared lanthanide "encapsulated sandwich" metallacrown complexes with excitation shifted toward lower energy. J. Am. Chem. Soc. 136, 1526-1534 (2014).

47. Hasegawa, Y., Hieda, R., Miyata, K., Nakagawa, T. \& Kawai, T. Brilliant triboluminescence of a lanthanide coordination polymer with low-vibrationalfrequency and non-centrosymmetric structural networks. Eur. J. Inorg. Chem. 2011, 4978-4984 (2011).

48. Hirai, Y. et al. Luminescent europium(III) coordination zippers linked with thiophene-based bridges. Angew. Chem. Int. Ed. 55, 12059-12062 (2016).

49. Hasegawa, Y. et al. Effective photo- and triboluminescent Eu(III) coordination polymers with rigid triangular spacer ligands. Chem. Eur. J. 23, 2666-2672 (2017).

50. Napier, G. D. R., Neilson, J. D. \& Shepherd, T. M. Charge-transfer excited state in tris(acetylacetonato) europium(III). Chem. Phys. Lett. 31, 328-330 (1975).

51. Faustino, W. M., Malta, O. L. \& de Sá, G. F. Theoretical modeling of thermally activated luminescence quenching through charge transfer states in lanthanide complexes. Chem. Phys. Lett. 429, 595-599 (2006).

52. Costa, S. M., de, B., Queimado, M. M. \& Frausto da Silva, J. J. R. Energy transfer in complexes between a crown ether and various lanthanide salts. J. Photochem. 12, 31-39 (1980).

53. Tsaryuk, V., Zolin, V. \& Legendziewicz, J. The structures of ligands and effects of the europium luminescence excitation. J. Lumin. 102-103, 744-750 (2003).

54. Faustino, W. M. et al. Photoluminescence of europium(III) dithiocarbamate complexes: Electronic structure, charge transfer and energy transfer. J. Phys. Chem. A 110, 2510-2516 (2006).

55. Regulacio, M. D. et al. Luminescence of $\operatorname{Ln}(\mathrm{III})$ dithiocarbamate complexes ( $\mathrm{Ln}$ $=\mathrm{La}, \mathrm{Pr}, \mathrm{Sm}, \mathrm{Eu}, \mathrm{Gd}$, Tb, Dy). Inorg. Chem. 47, 1512-1523 (2008).

56. Miranda, Y. C et al. The role of the ligand-to-metal charge-transfer state in the dipivaloylmethanate-lanthanide intramolecular energy transfer process. Eur. J. Inorg. Chem. 18, 3019-3027 (2015)

57. An, Y., Schramm, G. E. \& Berry, M. T. Ligand-to-metal charge-transfer quenching of the $\mathrm{Eu}^{3+}\left({ }^{5} \mathrm{D}_{1}\right)$ state in europium-doped tris(2,2,6,6-tetramethy3,5-heptanedionato)gadolinium (III). J. Lumin. 97, 7-12 (2002).

58. Yang, $C$. et al. A highly luminescent europium complex showing visible-lightsensitized red emission: Direct observation of the singlet pathway. Angew. Chem. Int. Ed. 43, 5010-5013 (2004).

59. Fu, L.-M. et al. Role of ligand-to-metal charge transfer state in nontriplet photosensitization of luminescent europium complex. J. Phys. Chem. A 114 4494-4500 (2010)

60. Lo, W.-S., Zhang, J., Wong, W.-T. \& Law, G.-L. Highly luminescent Smlll complexes with intraligand charge-transfer sensitization and the effect of solvent polarity on their luminescent properties. Inorg. Chem. 54, 3725-3727 (2015). 
61. Jorgensen, C. K. \& Brinen, J. S. Far ultra-violet absorption spectra of cerium(III) and europium(III) aqua ions. Mol. Phys. 6, 629-631 (1963).

62. Kusaba, M., Nakashima, N., Izawa, Y., Kawamura, W. \& Yamanaka, C. Higher yield of photoreduction of $\mathrm{Eu}^{3+}$ to $\mathrm{Eu}^{2+}$ with shorter wavelength irradiation. Chem. Phys. Lett. 197, 136-140 (1992).

63. Hasegawa, Y. et al. Enhanced luminescence and photomagnetic properties of surface-modified EuO nanocrystals. Angew. Chem. Int. Ed. 41, 2073-2075 (2002).

64. Hasegawa, Y. et al. EuO nanocrystal formation under ArF laser irradiation Chem. Lett. 32, 708-709 (2003).

65. Hasegawa, Y., Afzaal, M., O'Brien, P., Wada, Y. \& Yanagida, S. A novel method for synthesizing EuS nanocrystals from a single-source precursor under white LED irradiation. Chem. Commun. 242-243 (2005).

66. Meng, Q. et al. Thin film deposition and photodissociation mechanisms for lanthanide oxide production from tris(2,2,6,6-tetramethyl-3,5-heptanedionato)Ln(III) in laser-assisted MOCVD. Chem. Mater. 22, 6056-6064 (2010).

67. Ow, F. P., Berry, M. T., May, P. S. \& Zink, J. I. Wavelength and metal dependence in the photofragmentation of a gas-phase lanthanide $\beta$-diketonate complex. J. Phys. Chem. A 111, 4144-4149 (2007)

68. Xu H.-B., Chen X.-M., Zhang Q.-S., Zhang L.-Y. \& Chen Z.-N. Fluoride-enhanced lanthanide luminescence and white-light emitting in multifunctional $\mathrm{Al}_{3} \mathrm{Ln}$. $(\mathrm{Ln}=\mathrm{Nd}$, Eu, $\mathrm{Yb})$ heteropentanuclear complexes. Chem. Commun. 7318-7320 (2009).

69. Tang, C. W. \& Vanslyke, S. A. Organic electroluminescent diodes. Appl. Phys. Lett. 51, 913-915 (1987).

70. Smith, L. F., Blight, B. A., Park, H.J. \& Wang, S. Sensitizing Tb(III) and Eu(III) emission with triarylboron functionalized 1,3-diketonato ligands. Inorg. Chem. 53, 8036-8044 (2014)

71. Pasatoiu, T. D., Madalan, A. M., Kumke, M. U., Tiseanu, C. \& Andruh, M Temperature switch of $L M C T$ role: from quenching to sensitization of europium emission in a Znll-Eulll binuclear complex. Inorg. Chem. 49, 2310-2315 (2010).

72. Wei, T. et al. Co-existence of heterometallic $Z n_{2} E r$ and $Z n E r$ arrayed chromophores for the sensitization of near-infrared (NIR) luminescence. Inorg. Chem. Commun. 12, 1216-1219 (2009).

73. Abtab, S. M. T. et al. Tetranuclear homo- $\left(\mathrm{Zn}_{4}{ }_{4}\right.$ and $\left.\mathrm{Cd}_{4}{ }_{4}\right)$ and hetero-metal $\left(\mathrm{Zn}_{2}{ }_{2} \mathrm{~Tb}_{2}{ }_{2}\right.$ and $\left.\mathrm{Cd}_{2}{ }_{2} \mathrm{~Tb}_{2}{ }_{2}\right)$ complexes with a pair of carboxylate ligands in a rare $\eta_{2}: \eta_{2}: \mu_{4}$-bridging mode: syntheses, structures and emission properties. Dalton Trans. 42, 1848-1861 (2013).

74. Pasatoiu, T. D. et al. Study of the luminescent and magnetic properties of a series of heterodinuclear [ $\left.\mathrm{Zn}^{\prime \prime} \mathrm{Ln}{ }^{\mathrm{III}}\right]$ complexes. Inorg. Chem. 50, 5879-5889 (2011)

75. Xu, H.-B., Zhong, Y.-T., Zhang, W.-X., Chen, Z.-N. \& Chen, X.-M. Syntheses, structures and photophysical properties of heterotrinuclear $Z \mathrm{n}_{2} \mathrm{Ln}$ clusters $(\mathrm{Ln}=\mathrm{Nd}$, Eu, Tb, Er, Yb). Dalton Trans. 39, 5676-5682 (2010).

76. Chi, Y.-X., Niu, S.-Y., Wang, R., Jin, J. \& Zhang, G.-N. Syntheses, structures and photophysical properties of heteronuclear Zn-Ln coordination complexes. J. Lumin. 131, 1707-1713 (2011)

77. Li, Z. Q., Hou, Z. H., Ha, D. H. \& Li, H. R. A ratiometric luminescent thermometer co-doped with lanthanide and transition metals. Chem. Asian J. 10 2719-2723 (2015).

78. Akine, S., Utsuno, F., Taniguchi, T. \& Nabeshima, T. Dinuclear complexes of the $\mathrm{N}_{2} \mathrm{O}_{2}$ oxime chelate ligand with zinc(II)-lanthanide(III) as a selective sensitization system for $\mathrm{Sm}^{3+}$. Eur. J. Inorg. Chem. 2010, 3143-3152 (2010).

79. Swinburne, A. N., Paterson, M. J., Beeby, A. \& Steed, J. W. Fluorescent twist-on sensing by induced-fit anion stabilisation of a planar chromophore. Chem. Eur. J. 16, 2714-2718 (2010)

80. Zhao, S. et al. Effective enhancement of near-infrared emission by carbazole modification in the $\mathrm{Zn}-\mathrm{Nd}$ bimetallic Schiff-base complexes. Inorg. Chem. Commun. 20, 41-45 (2012)

81. Yamamoto, M., Nakanishi, T., Kitagawa, Y., Fushimi, K. \& Hasegawa, Y. Luminescent Eu(III) coordination polymer cross-linked with Zn(II) complexes. Mater. Lett. 167, 183-187 (2016).

82. Sykes, D. et al. d-f energy transfer in a series of Irlll/Eulll dyads: energy-transfer mechanisms and white-light emission. Inorg. Chem. 50, 11323-11339 (2011).

83. Jones, J. E., Jenkins, R. L., Hicks, R. S., Hallett, A. J. \& Pope, S. J. A. Water-soluble, luminescent iridium(III)-ytterbium(III) complexes using dipyrido[3,2-a:2', $\left.3^{\prime}-c\right]$ phenazine derivatives as bridging units. Dalton Trans. 41, 10372-10381 (2012).
84. Jiang, W. et al. A green-emitting iridium complex used for sensitizing europium ion with high quantum yield. Inorg. Chim. Acta 459, 124-130 (2017)

85. Tart, N. M. Sykes, D., Sazanovich, I., Tidmarsh, I. S. \& Ward, M. D. Iridium(III) luminophores as energy donors for sensitised emission from lanthanides in the visible and near-infrared regions. Photochem. Photobiol. Sci. 9, 886-889 (2010)

86. Tamayo, A. B. et al. Synthesis and characterization of facial and meridional tris-cyclometalated Iridium(III) complexes. J. Am. Chem. Soc. 125, 7377-7387 (2003).

87. Lian, P., Wei, H., Zheng, C., Nie, Y., Bian, J., Bian, Z. \& Huang, C. Synthesis, characteristics and photoluminescent properties of novel Ir-Eu heteronuclear complexes containing 2-carboxyl-pyrimidine as a bridging ligand. Dalton Trans. 40, 5476-5482 (2011).

88. Jiang, W., Lou, B., Wang, J., LV, H., Bian, Z., \& Huang, C. The influence of triplet energy levels of bridging ligands on energy transfer processes in $\mathrm{Ir}(\mathrm{III}) / \mathrm{Eu}(\mathrm{III})$ dyads. Dalton Trans. 40, 11410-11418 (2011)

89. Sykes, D. \& Ward, M. D. Visible-light sensitisation of Tb(III) luminescence using a blue-emitting $\operatorname{Ir}(\mathrm{III})$ complex as energy-donor. Chem. Commun. $\mathbf{4 7}$ 2279-2281 (2011)

90. Edkins, R. M., Sykes, D., Beeby, A. \& Ward, M. D. Combined two-photon excitation and $\mathrm{d}-\mathrm{f}$ energy-transfer in Ir/lanthanide dyads with time-gated selection from a two-component emission spectrum. Chem. Commun. $\mathbf{4 8}$ 9977-9979 (2012)

91. Nonat, A. M., Allain, C., Faulkner, S. \& Gunnlaugsson, T. Mixed d-f $f_{3}$ coordination complexes possessing improved near-infrared (NIR) lanthanide luminescent properties in aqueous solution. Inorg. Chem. 49, 8449-8456 (2010).

92. Charbonnière, L. J. et al. $\operatorname{Ln} n_{2} M$ complexes $(M=R u, R e)$ derived from a bismacrocyclic ligand containing a 4,4'-dimethyl-2,2'-bipyridyl bridging unit Dalton Trans. 42, 3667-3681 (2013).

93. Di Piazza, E. et al. d-f Heterobimetallic association between ytterbium and ruthenium carbon-rich complexes: Redox commutation of near-IR luminescence. J. Am. Chem. Soc. 133, 6174-6176 (2011).

94. Wang, L., Xie, Z., Dang, S. \& Sun, Z. Self-assembly of tunable heterometallic Ln-Ru coordination polymers with near-infrared luminescence and magnetocaloric effect. Chem. Eur. J. 23, 2852-2857 (2017).

95. Hasegawa, Y. et al. Enhanced electric dipole transition in lanthanide complex with organometallic ruthenocene units. J. Phys. Chem. A 119, 4825-4833 (2015).

96. Ward, M. D. Mechanisms of sensitization of lanthanide(III)-based luminescence in transition metal/lanthanide and anthracene/lanthanide dyads. Coord. Chem. Rev. 254, 2634-2642 (2010).

97. Tropiano, M. et al. Synthesis and Spectroscopic study of $d-f$ hybrid lanthanide complexes derived from triazolyIDO3A. Organometallics 31, 5673-5676 (2012)

98. Xu, H. B., Zhang, L. Y., Chen, X. M., Li, X. L. \& Chen, Z. N. Modulation of Pt $\rightarrow \mathrm{Ln}$ energy transfer in PtLn $n_{2}(L n=N d, E r, Y b)$ complexes with 2,2'-bipyridyl/2,2':6' 2"-terpyridyl ethynyl ligands. Cryst. Growth Des. 9, 569-576 (2009).

99. Li, J., Wang, J.-Y. \& Chen, Z.-N. Sensitized Eulll luminescence through energy transfer from $\mathrm{PtM}_{2}\left(\mathrm{M}=\mathrm{Ag}\right.$ or $\mathrm{Au}$ ) alkynyl chromophores in $\mathrm{PtM}_{2} \mathrm{Eu}_{2}$ heteropentanuclear complexes. J. Mater. Chem. C 1, 3661-3668 (2013).

100. Maynard, B. A. et al. Emission enhancement through dual donor sensitization: modulation of structural and spectroscopic properties in a series of europium tetracyanoplatinates. Inorg. Chem. 48, 6425-6435 (2009).

101. Li, X. L., Zhang, K. J., Li, J. J., Cheng, X. X. \& Chen, Z. N. Dual luminescent dinuclear gold(I) complexes of terpyridyl-functionalized alkyne ligands and their efficient sensitization of Eu-III and Yb-III luminescence. Eur. J. Inorg. Chem. 2010, 3449-3457 (2010).

102. Iki, N., Hiro-oka, S., Tanaka, T., Kabuto, C. \& Hoshino, H. Highly efficient nearinfrared-emitting lanthanide(III) complexes formed by heterogeneous selfassembly of $\mathrm{Ag}^{\prime}, \mathrm{Ln}^{\mathrm{II \prime}}$, and thiacalix[4]arene-p-tetrasulfonate in Aqueous Solution $\left(\mathrm{Ln}^{\mathrm{III}}=\mathrm{Nd} \mathrm{d}^{\mathrm{II}}, \mathrm{Yb} \mathrm{b}^{\mathrm{II}}\right)$. Inorg. Chem. 51, 1648-1656 (2012)

103. Yang, X., Schipper, D., Jones, R. A., Lytwak, L. A. \& Holliday, B. J. et al Aniondependent self-assembly of near-infrared luminescent 24- and 32-metal Cd-Ln complexes with drum-like architectures. J. Am. Chem. Soc. 135 8468-8471 (2014).

104. Song, X. Q., Cheng, G. Q. \& Liu, Y. A. Enhanced Tb(III) luminescence by $d^{10}$ transition metal coordination. Inorg. Chim. Acta 450, 386-394 (2016). 
105. Omagari, S. et al. Critical role of energy transfer between terbium ions for suppression of back energy transfer in nonanuclear terbium clusters. Sci. Rep. 6, 37008 (2016).

106. Miyata, K. et al. Chameleon luminophore for sensing temperatures: control of metal-to-metal and energy back transfer in lanthanide coordination polymers. Angew. Chem. Int. Ed. 52, 6413-6416 (2013).

107. Hatanaka, M. et al. Organic linkers control the thermosensitivity of the emission intensities from Tb(III) and Eu(III) in a chameleon polymer. Chem. Sci. 8. 423-429 (2017)

108. Hatanaka, M. \& Morokuma, K. Exploring the reaction coordinates for $f-f$ emission and quenching of lanthanide complexes-thermosensitivity of terbium(III) luminescence. J. Chem. Theory Comput. 10, 4184-4188 (2014).

109. Hirai, Y., Nakanishi, T., Miyata, K., Fushimi, K. \& Hasegawa, Y. Thermo-sensitive luminescent materials composed of $\mathrm{Tb}(\mathrm{III})$ and Eu(III) complexes. Mater. Lett. 130, 91-93 (2014).

110. Iffanullah, M., Iftikhar \& Inorg, K. New hetero-dilanthanide complexes containing $L n_{1}(f o d)_{3}$ and $L n_{2}(f \circ d)_{3}$ fragments ( $L n=P r-N d ; N d-S m ; E u-T b$ and Ho-Er) linked by bis-diimine bridging ligand. Inorg. Chem. Commun. 13, 694-698 (2010).

111. Hirai, Y. et al. Glass transition properties and temperature-sensitive luminescence of lanthanide coordination glasses linked by thienyl, naphthyl, and phenyl bridges with ethynyl group. Bull. Chem. Soc. Jpn. 90, 322-326 (2017).

112. Wang, H., Zhao, D., Cui, Y., Yang, Y. \& Qian, G. A Eu/Tb-mixed MOF for luminescent high-temperature sensing. J. Sol. State Chem. 246, 341-345 (2017).

113. Wei, Y., Sa, R., Li, Q. \& Wu, K. Highly stable and sensitive LnMOF ratiometric thermometers constructed with mixed ligands. Dalton Trans. 44, 3067-3074 (2015).

114. Nakajima, A., Nakanishi, T., Kitagawa, Y., Fushimi, K. \& Hasegawa, Y. Thermosensitive luminescent lanthanide complex with two photosensitized ligands. Sens. Mater. 28, 845-850 (2016).

115. Zhou, Y., Yan, B. \& Lei, F. Postsynthetic lanthanide functionalization of nanosized metal-organic frameworks for highly sensitive ratiometric luminescent thermometry. Chem. Commun. 50, 15235-15238 (2014).

116. Rocha, J., Brites, C. D. S. \& Carlos, L. D. Lanthanide organic framework luminescent thermometers. Chem. Eur. J. 22, 14782-14795 (2016).

117. Cui, Y. J., Chen, B. L. \& Qian, G. D. Lanthanide metal-organic frameworks for luminescent sensing and light-emitting applications. Coord. Chem. Rev. 273-274, 76-86 (2014)

118. Yi, F.-Y., Chen, D., Wu, M.-K., Han, L. \& Jiang, H.-L. Chemical sensors based on metal-organic frameworks. ChemPlusChem 81, 675-690 (2016).

119. DVries, R. F. et al. Multimetal rare earth MOFs for lighting and thermometry: tailoring color and optimal temperature range through enhanced disulfobenzoic triplet phosphorescence. J. Mater. Chem. C 1, 6316-6324 (2013).

120. Matthes, P. R. et al. Luminescence tuning of MOFs via ligand to metal and metal to metal energy transfer by co-doping of ${ }_{\infty}^{2}\left[\mathrm{Gd}_{2} \mathrm{Cl}_{6}(\mathrm{bipy})_{3}\right] \cdot 2$ bipy with europium and terbium. J. Mater. Chem. 22, 10179-10187 (2012).

121. Zhang, H. B. et al. A highly luminescent chameleon: fine-tuned emission trajectory and controllable energy transfer. J. Mater. Chem. C 2, 1367-1371 (2014)

122. Liu, L., Zhang, X., Fu, G., Lü, X. \& Wong, W.-K. et al Singe-component $\mathrm{Zn}^{2+}$-Eu ${ }^{+}-\mathrm{Tb}^{3+}$-containing and $\mathrm{Zn}^{2+}-\mathrm{Eu}^{3+}-\mathrm{Tb}^{3+}-\mathrm{Gd}^{3+}$-containing metallopolymertype materials with ultra-high color rendering index white-light. Dyes Pigm 141, 137-147 (2017)

123. Tang, Q. et al. Color tuning and white light emission via in situ doping of luminescent lanthanide metal-organic frameworks. Inorg. Chem. 53, 289-293 (2014)

124. Ye, J.W. et al. Mixed-lanthanide porous coordination polymers showing range-tunable ratiometric luminescence for $\mathrm{O}_{2}$ sensing. Inorg. Chem. 56, 4238-4243 (2017).

125. Auzel, F. Upconversion and anti-stokes processes with $\mathrm{F}$ and $\mathrm{D}$ ions in solids. Chem. Rev. 104, 139-174 (2004).

126. Aboshyan-Sorgho, L. et al. Near-infrared $\rightarrow$ visible light upconversion in a molecular trinuclear d-f-d complex. Angew. Chem. Int. Ed. 50, 4108-4112 (2011).

127. Suffren, Y. et al. Taming lanthanide-centered upconversion at the molecular level. Inorg. Chem. 55, 9964-9972 (2016).

128. Nonat, A. et al. Room temperature molecular up conversion in solution. Nat. Commun. 7, 11978 (2016)
129. Souri, N. et al. Upconverted photosensitization of Tb visible emission by NIR Yb excitation in discrete supramolecular heteropolynuclear complexes. J. Am. Chem. Soc. 139, 1456-1459 (2017).

130. Blackburn, O. A. et al. Luminescence and upconversion from thulium(III) species in solution. Phys. Chem. Chem. Phys. 14, 13378-13384 (2012).

131. Ishii, A. \& Hasegawa, M. Solar-pumping upconversion of interfacial coordination nanoparticles. Sci. Rep. 7, 41446 (2017).

132. Kido, J., Nagai, K. \& Ohashi, Y. Electroluminescence in a terbium complex Chem. Lett. 19, 657-660 (1990).

133. Kawamura, Y. et al. Observation of neodymium electroluminescence. Appl. Phys. Lett. 74, 3245-3247 (1999).

134. Xu, H., Sun, Q., An, Z., Wei, Y. \& Liu, X. Electroluminescence from europium(III) complexes. Coord. Chem. Rev. 293-294, 228-249 (2015).

135. Wang, J. Z. et al. Solution-processible brilliantly luminescent Eulll complexes with host-featured phosphine oxide ligands for monochromic red-lightemitting diodes. Chem. Eur. J. 20, 11137-11148 (2014).

136. Xu, H., Zhu, R., Zhao, P. \& Huang, W. Monochromic red-emitting nonconjugated copolymers containing double-carrier-trapping phosphine oxide $\mathrm{Eu}^{3+}$ segments: toward bright and efficient electroluminescence. J. Phys. Chem. C 115, 15627-15638 (2011).

137. Hasegawa, Y. et al. Luminescent thin films composed of nanosized europium coordination polymers on glass electrodes. ChemPlusChem 81, 187-193 (2016)

138. $\mathrm{Xu}, \mathrm{H}$. et al. A unique white electroluminescent one-dimensional europium (iii) coordination polymer. J. Mater. Chem. C 3, 1893-1903 (2015).

139. Zinna, F., Giovanella, U. \& Bari, L. D. Highly circularly polarized electroluminescence from a chiral europium complex. Adv. Mater. 27, 1791-1795 (2015).

140. Cui, R. et al. High performance red phosphorescent organic electroluminescent devices with characteristic mechanisms by utilizing terbium or gadolinium complexes as sensitizers. J. Mater. Chem. C 5, 2066-2073 (2017)

141. Adachi, C., Baldo, M. A., Thompson, M. E. \& Forrest, S. R. Nearly 100\% internal phosphorescence efficiency in an organic light-emitting device. J. Appl. Phys. 90, 5048-5051 (2001).

142. Uoyama, H., Goushi, K, Shizu, K., Nomura, H. \& Adachi, C. Highly efficient organic light-emitting diodes from delayed fluorescence. Nature 492 234-238 (2012)

143. Lee, S. Y., Yasuda, T., Komiyama, H., Lee, J. \& Adachi, C. Thermally activated delayed fluorescence polymers for efficient solution-processed organic lightemitting diodes. Adv. Mater. 28, 4019-4024 (2016).

144. Lee, S. Y., Adachi, C. \& Yasuda, T. High-efficiency blue organic light-emitting diodes based on thermally activated delayed fluorescence from phenoxaphosphine and phenoxathiin derivatives. Adv. Mater. 28, 4626-4631 (2016).

145. Hasegawa, Y, Tsuruoka, S., Yoshida, T., Kawai, H. \& Kawai, T. Enhanced deepred luminescence of tris(hexafluoroacetylacetonato)samarium(III) complex with phenanthroline in solution by control of ligand coordination. J. Phys. Chem. A 112, 803-807 (2008).

146. Wiedemann, E. \& Schmidt, G. C. Thermoluminescence induced by electron beams in alkali halides. Ann. Phys. Chem. 54, 604-625 (1895).

147. Walton, A. J. Triboluminescence. Adv. Phys. 26, 887-948 (1977).

148. Zink, J. I. Triboluminescence. Acc. Chem. Res. 11, 289-295 (1978).

149. Olawale, D. O. et al. Progress in triboluminescence-based smart optical sensor system. J. Lumin. 131, 1407-1418 (2011).

150. Wang, X. D. et al. Dynamic pressure mapping of personalized handwriting by a flexible sensor matrix based on the mechanoluminescence process. Adv. Mater. 27, 2324-2331 (2015).

151. Olawale, D. O. et al. Real time failure detection in unreinforced cementitious composites with triboluminescent sensor. J. Lumin. 147, 235-241 (2014).

152. Fontenot, R. S., Hollerman, W. A., Bhat, K. N., Aggarwal, M. D. \& Penn, B. G. Incorporating strongly triboluminescent europium dibenzoylmethide triethylammonium into simple polymers. Polym. J. 46, 111-116 (2014)

153. Hurt, C. R. McAvoy, N. Bjorklund, S. \& Filipescu, N. High intensity triboluminescence in europium tetrakis (dibenzoylmethide)-triethylammonium. Nature 212, 179-180 (1966).

154. Sweeting, L. M. \& Rheingold, A. L. Crystal disorder and triboluminescence: triethylammonium tetrakis(dibenzoylmethanato)europate. J. Am. Chem. Soc 109, 2652-2658 (1987).

155. Takada, N., Sugiyama, J., Katoh, R., Minami, N. \& Hieda, S. Mechanoluminescent properties of europium complexes. Synth. Met. 91, 351-354 (1997) 
156. George, T. M., Sajan, M. J., Gopakumar, N. \& Reddy, M. L. P. Bright red luminescence and triboluminescence from PMMA-doped polymer film materials supported by $\mathrm{Eu}^{3+}$-triphenylphosphine based beta-diketonate and 4,5-bis(diphenylphosphino)-9,9-dimethylxanthene oxide. J. Photochem. Photobiol. A 317, 88-99 (2016).

157. Cotton, F. A., Daniels, L. M. \& Huang, P. Refutation of an alleged example of a disordered but centrosymmetric triboluminescent crystal. Inorg. Chem. Commun. 4, 319-321 (2001).

158. Zhang, S. et al. Eu-MOFs with 2-(4-carboxyphenyl)imidazo[4,5-f]-1,10-phenanthroline and ditopic carboxylates as coligands: synthesis, structure, high thermostability, and luminescence properties. Inorg. Chem. 53, 10952-10963 (2014).

159. Bukvetskii, B. V., Mirochnik, A. G., Zhikhareva, P. A. \& Karasev, V. E. Crystal structure and triboluminescence of the $\left[\mathrm{Eu}(\mathrm{TTA})_{2}\left(\mathrm{NO}_{3}\right)(\mathrm{TPPO})_{2}\right]$ complex. J. Struct. Chem. 47, 575-580 (2006).

160. Bukvetskii, B. V., Shishov, A. S. \& Mirochnik, A. G. Triboluminescence and crystal structure of the centrosymmetric complex $\left[\mathrm{Tb}\left(\mathrm{NO}_{3}\right)_{2}(\mathrm{Acac})\right.$ (Phen) 2 ] $\mathrm{H}_{2} \mathrm{O}$. Luminescence 31, 1329-1334 (2016).

161. Li, X.-L., Zheng, Y., Zuo, J.-L., Song, Y. \& You, X.-Z. Synthesis, crystal structures and triboluminescence of a pair of Eu(III)-based enantiomers. Polyhedron $\mathbf{2 6}$ 5257-5262 (2007).

162. Li, D.-P. et al. Synthesis and physical properties of two chiral terpyridyl europium(III) complexes with distinct crystal polarity. Eur. J. Inorg. Chem. 2009, 4844-4849 (2009).

163. Fontenot, R. S., Hollerman, W. A., Bhat, K. N. \& Aggarwal, M. D. Synthesis and characterization of highly triboluminescent doped europium tetrakis compounds. J. Lumin. 132, 1812-1818 (2012)

164. Chen, X.-F. et al. Crystal structures and triboluminescent activities of samarium(III) complexes. J. Coord. Chem. 52, 97-110 (2000).

165. Akerboom, S., Meijer, M. S., Siegler, M. A., Fu, W. T. \& Bouwman, E. Structure, photo- and triboluminescence of the lanthanoid dibenzoylmethanates: $\mathrm{HNEt}_{3}\left[\mathrm{Ln}(\mathrm{dbm})_{4}\right]$. J. Lumin. 145, 278-282 (2014).

166. Biju, S. et al. Brilliant photoluminescence and triboluminescence from ternary complexes of Dy ${ }^{\mathrm{III}}$ and $\mathrm{Tb}^{\mathrm{III}}$ with 3-phenyl-4-propanoyl-5-isoxazolonate and a bidentate phosphine oxide coligand. Inorg. Chem. 52 8750-8758 (2013).

167. Chen, X.-F. et al. Triboluminescence and crystal structures of non-ionic europium complexes. J. Mater. Chem. 9, 2919-2922 (1999).

168. Eliseeva, S. V. et al. Highly luminescent and triboluminescent coordination polymers assembled from lanthanide $\beta$-diketonates and aromatic bidentate O-donor ligands. Inorg. Chem. 49, 9300-9311 (2010).

169. Mikhalyova, E. A. et al. Manifestation of $\pi-\pi$ Stacking Interactions in luminescence properties and energy transfer in aromatically-derived Tb, Eu and Gd tris(pyrazolyl)borate complexes. Inorg. Chem. 54, 3125-3133 (2015)

170. Teotonio, E. E. S. et al. Evaluation of intramolecular energy transfer process in the lanthanide(III) bis- and tris-(TTA) complexes: photoluminescent and triboluminescent behavior. J. Lumin. 128, 190-198 (2008).

171. Mikhalyova, E. A. et al. Crystal structures and intense luminescence of tris(3(2'-pyridyl)-pyrazolyl)borate $\mathrm{Tb}^{3+}$ and $\mathrm{Eu}^{3+}$ complexes with carboxylate coligands. Dalton Trans. 46, 3457-3469 (2017).

172. Hirai, Y. et al. Triboluminescence of lanthanide coordination polymers with face-to-face arranged substituents. Angew. Chem. Int. Ed. 56, 7171-7175 (2017)

173. Fontenot, R. S., Hollermana, W. A., Aggarwal, M. D., Bhat, K. N. \& Goedekea, S. M. A versatile low-cost laboratory apparatus for testing triboluminescent materials. Measurement 45, 431-436 (2012).

174. Wong, H.-Y., Lo, W.-S., Chan, W. T. K. \& Law, G. L. Mechanistic investigation of inducing triboluminescence in lanthanide(III) $\beta$-diketonate complexes. Inorg. Chem. 56, 5135-5140 (2017).

175. Incel, A., Emirdag-Eanes, M., McMillen, C. D. \& Demir, M. M. Integration of triboluminescent $\mathrm{EuD}_{4} \mathrm{TEA}$ crystals to transparent polymers: impact sensor application. ACS Appl. Mater. Interfaces 9, 6488-6496 (2017).
176. Hasegawa, Y. et al. Luminescent polymer containing the Eu(III) complex having fast radiation rate and high wmission quantum efficiency. J. Phys. Chem. A 107, 1697-1702 (2003)

177. Nakamura, K et al. Enhanced lasing properties of dissymmetric Eu(III) complex with bidentate phosphine ligands. J. Phys. Chem. A. 111, 3029-3037 (2007).

178. Miyata, K. et al. Remarkable luminescence properties of lanthanide complexes with asymmetric dodecahedron structures. Chem. Eur. J. 17, 521-528 (2011).

179. Hasegawa, Y. et al. Effect of ligand polarization on asymmetric structural formation for strongly luminescent lanthanide complexes. Eur. J. Inorg. Chem. 2013, 5913-5918 (2013).

180. Yanagisawa, K. et al. Seven-coordinate luminophores: brilliant luminescence of lanthanide complexes with $C_{3 v}$ geometrical structures. Eur. J. Inorg. Chem. 2015, 4769-4774 (2015).

181. Yanagisawa, K., et al. Enhanced luminescence of asymmetrical sevencoordinate Eull complexes including LMCT perturbation. Eur. J. Inorg. Chem. 2017, in press.

182. Iwamuro, M. et al. Luminescence of $\mathrm{Nd}^{3+}$ complexes with some asymmetric ligands in organic solutions. J. Lumin. 79, 29-38 (1998)

183. Nakamura, K., Hasegawa, Y., Wada, Y. \& Yanagida, S. Novel luminescent Eu(III) complex with remarkably narrow emission band. Chem. Phys. Lett. 398 500-504 (2004).

184. Hasegawa, Y. et al. Enhanced emission of deuterated tris(hexafluoroacetylacetonato) neodymium(III) complex in solution by suppression of radiationless transition via vibrational excitation. J. Phys. Chem. 100 10201-10205 (1996).

185. Nakamura, K. et al. High lasing oscillation efficiency of Eu(III) complexes having remarkably sharp emission band. J. Alloy Compd. 408, 771-775 (2006).

186. Hasegawa, Y. et al. Enhancement of luminescence of $\mathrm{Nd}^{3+}$ complexes with deuterated hexafluoroacetylacetonato ligands in organic solvent. Chem. Phys. Lett. 248, 8-12 (1996).

187. Hasegawa, Y. et al. Characteristic emission of $\beta$-diketonato $\mathrm{Nd}^{3+}$ complexes dressed with perfluoroalkyl groups in DMSO-d 6 . Chem. Phys. Lett. 260 173-177 (1996). S..

188. Hasegawa, Y. et al. Enhanced emission of $\mathrm{Nd}^{3+}$ in liquid systems: formation of symmetrical rigid shells of tightly solvated DMSO molecules and weakly coordinated low-vibrational $\beta$-diketonato ligands. Bull. Chem. Soc. Jpn. 71 2573-2581 (1998).

189. Yanagida, S. et al. Strategies for enhancing photoluminescence of $\mathrm{Nd}^{3+}$ in liquid media. Coord. Chem. Rev. 171, 461-480 (1998).

190. Hasegawa, Y. et al. Enhanced luminescence of lanthanide(III) complexes in polymer matrices. Chem. Lett. 1, 35-36 (1999).

191. Wada, Y. et al. High efficiency near-IR emission of $\mathrm{Nd}(\mathrm{III})$ based on lowvibrational environment in cages of nanosized zeolites. J. Am. Chem. Soc. $122,8583-8584$ (2000).

192. Yanagida, S., Hasegawa, Y. \& Wada, Y. Remarkable luminescence of novel $\mathrm{Nd}$ (III) complexes with low-vibrational hexafluoroacetylacetone and DMSO-d molecule. J. Lumin. 87, 995-998 (2000).

193. Hasegawa, $\boldsymbol{H}$. et al. Luminescence of novel neodymium sulfonylaminate complexes in organic media. Angew. Chem. Int. Ed. 39, 357-360 (2000).

194. Ryo, M. et al. Spectroscopic study on strongly luminescent $\mathrm{Nd}(\mathrm{III})$ exchanged zeolite: $\mathrm{TMA}^{+}$-containing FAU type zeolite as a suitable host for ship-in-bottle synthesis. J. Mater. Chem. 12, 1748-1753 (2002).

195. Ryo, M. Wada, Y, Okubo, T, Hasegawa, Y. \& Yanagida, S. Intrazeolite nanostructure of $\mathrm{Nd}$ (III) complex giving strong near-infrared luminescence. J. Phys. Chem. B 107, 11302-11306 (2003).

196. Hasegawa, Y., Sogabe, K., Wada, Y. \& Yanagida, S. Low-vibrational luminescent polymers including tris(bis-perfluoromethane and ethanesulfonylaminate) neodymium(III) with 8 coordinated DMSO-d. J. Lumin. 101, 235-242 (2003).

197. Hasegawa, Y. et al. Molecular design of luminescent Eu(III) complexes as lanthanide lasing material and their optical properties. J. Alloy Compd. $\mathbf{4 0 8}$ 669-674 (2006). 